\title{
Smart Sustainable Cities: Using a Fuzzy Inference System to Determine their Global Score
}

\author{
By Oswaldo Redig de Campos Filho, Waléria Guerreiro Lima \\ \& Rodrigo Felipe Albuquerque Paiva de Oliveira
}

Abstract- This article assumes the premise that there is no alternative other than sustainable development. The necessary escalation to sustainability will force organizations and public administration to adopt an adequate stand to the sustainable development, mainly when it comes to the promotion of policies that shall guarantee the fulfillment of the triple bottom line (sustainability tripod) for the next generations, also respecting cultural and political issues. This research has collected data from four cities all around the globe using forty-six 'ISO 37.120:2018' core indicators. We have compared, using an adapted fuzzy logic model, the general sustainability score of cities in developing and developed countries. The event of trying to determine a methodology that can be used by any city of any country requires a considerable amount of researching, especially when it comes to choosing which better indicators are fit to the challenge - at the end of the article, we offer a schematic of a smart sustainable city, which we have called "sustainability mandala". Using the same system (with different weighs for each variable,), those answers will help public managers to understand their indexes as a result of positive efforts over the indicators, always on the pursuit of a really sustainable society.

Keywords: sustainability; ISO 37120; sustainable development; fuzzy logic.

GJSFR-H Classification: FOR Code: 059999

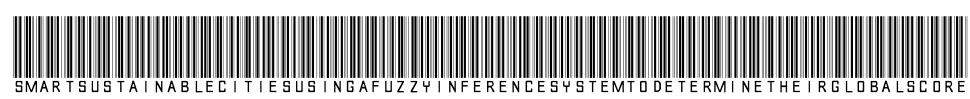

Strictly as per the compliance and regulations of:

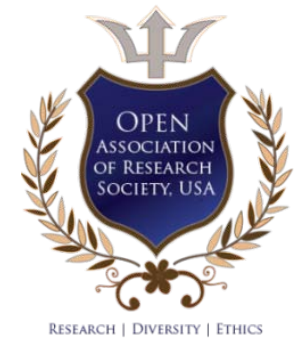

(c) 2019. Oswaldo Redig de Campos Filho, Waléria Guerreiro Lima \& Rodrigo Felipe Albuquerque Paiva de Oliveira. This is a research/review paper, distributed under the terms of the Creative Commons Attribution-Noncommercial 3.0 Unported License http://creativecommons.org/licenses/by-nc/3.0/), permitting all non commercial use, distribution, and reproduction in any medium, provided the original work is properly cited. 


\title{
Smart Sustainable Cities: Using a Fuzzy Inference System to Determine their Global Score
}

\author{
Oswaldo Redig de Campos Filho ${ }^{\alpha}$, Waléria Guerreiro Lima ${ }^{\sigma}$ \\ $\&$ Rodrigo Felipe Albuquerque Paiva de Oliveira $^{\rho}$
}

\begin{abstract}
This article assumes the premise that there is no alternative other than sustainable development. The necessary escalation to sustainability will force organizations and public administration to adopt an adequate stand to the sustainable development, mainly when it comes to the promotion of policies that shall guarantee the fulfillment of the triple bottom line (sustainability tripod) for the next generations, also respecting cultural and political issues. This research has collected data from four cities all around the globe using fortysix 'ISO 37.120:2018' core indicators. We have compared, using an adapted fuzzy logic model, the general sustainability score of cities in developing and developed countries. The event of trying to determine a methodology that can be used by any city of any country requires a considerable amount of researching, especially when it comes to choosing which better indicators are fit to the challenge - at the end of the article, we offer a schematic of a smart sustainable city, which we have called "sustainability mandala". Using the same system (with different weighs for each variable,), those answers will help public managers to understand their indexes as a result of positive efforts over the indicators, always on the pursuit of a really sustainable society.
\end{abstract}

Keywords: Sustainability; ISO 37120; sustainable development; fuzzy logic.

\section{INTRODUCTION}

$\Lambda$ ccording to the United Nations (2005), cities inhabitant number will increase in 2.5 billion Ipeople until 2050. By then, UN estimates that more than $68 \%$ of the world population will be living in urban areas (UN, The 2018 Revision of the World Urbanization Prospects). This growth in urban population implies significant challenges to natural resources usage, biodiversity, socioeconomic factors, among others (OCDE, 2012), and it also leads us to believe that cities all around the globe will need a significant amount of investments in infrastructure (Ramaswami et al., 2016). According to European Commission Directorate-General for Research and Innovation (2015), the term 'infrastructure' can be defined by any means as a whole system that provides water, sanitation, energy, food, shelter, transportation, communication, solid residue and public space management, all of them essential to promote human well-being and economic development. Contemporary cities are seen as a source of big social problems

Author a $\sigma$ : Centro Universitário dos Guararapes, Jaboatão dos Guararapes, PE, 54400-160, Brazil. e-mail: waguelima@gmail.com Author p: Universidade de Pernambuco, Recife, PE, 50100-010, Brazil.
(Bibrie Krogstie, 2017), once they make use of $70 \%$ of the world's available resources (being great energy consumers) and, therefore, having an immense contribution to greenhouse gas emissions (GHG) - also because of the density of urban population and the intensity of their economic and social activities (not mentioning the inefficiency of their built areas). All above-mentioned shows the need for discussions about the role of sustainability on urban planning, to find answers to the challenges of the fast- evolving urbanization process - as well as the lack of sustainability of the actual urban forms.

Regarding Bulkeley e Betsill (2005), the best way for cities to restructure would be to adopt long-term approaches that focus on sustainability. Thus, it is necessary to design urban systems that manage their growth and development in a way that mitigate the adverse effects that these cities cause (Antrop, 2004). Urban systems are considered systems that operate and organize life in a built environment, taking into account infrastructure, ecosystem services, human services and, of course, its management process (Bibri e Krogstie, 2017). Still, it is essential to understand that these systems are sensing an increasing pressure due to the enormous challenge sustainability brings, allied to the biggest wave of urbanization in history. The existing built environment is already associated with numerous negative environment, social and economic impacts including unsustainable energy use and concomitant GHG emissions -, increased air and water pollution, environmental degradation, poor land use, social deprivation, inefficient mobility and accessibility, restricted public safety and health, outdated digital infrastructures, and even the shape of the cities (that affects people, resources, habitat, and climate) (Colldahl, e Kelemen, 2013; Jabareen, 2006).

Although it is not easy to define sustainability, it is necessary to consider it is a concept that leverage the knowledge about how human and natural systems interact, for designing, developing, implementing, evaluating and improving engineering with practical solutions and interventions. This solution shall support the idea of social and ecological systems in equilibrium - as well as nurturing and maintaining links between scientific research and technological innovation -, and public policy and administration processes in relevance to sustainability (Bibri e Krogstie, 2017). Together with 
this approach, urban sustainability denotes the desired state in which society strives to reach a balance between protection, integration, economic development, equity and social justice, all as long-term goals through strategic urban development process (Bibri, 2013). In this way, one can define smart sustainable city defined as a modern environment that uses technologies to improve the quality of life, competitiveness and operational efficiency of urban services, ensuring the availability of resources for present and future generations regarding social, economic and environmental aspects (Kondepudi, 2014).

A city is considered sustainable when it can keep or improve the health of its environmental system, reduce degradation and anthropic impact, reduce social inequality and provide basic living conditions, as well as a healthy and safe environment (and also build political agreements that allow the society to face present and future challenges). Thus, to be considered sustainable, a city does not only have to provide its inhabitant's balanced environmental conditions, but to do so by maintaining low levels of negative externalities over other regions (near or far) and the future. It implies focusing not only on the local scale of sustainability, but also on the regional (made of the interactions with the surrounding areas) and global ones (Mcgranahan e Satterthwaite, 2002; Miller E Small, 2003).

It is important to emphasize that one of the challenges to building sustainable development is to create measurement instruments capable of providing information that makes it possible to evaluate the degree of sustainability of societies, monitor their development trends, and help on the definition of improvement goals (Polaz e Teixeira, 2009). But if sustainability is not easily defined, even more complex is the way to measure it. Such measuring is only possible by 'reading' the environment through previously established indicators (Gagliardi et al., 2007). These indicators allow one to understand the state of the environment in its various aspects, selecting - among all available information - those characteristics that can explain a particular situation, with a descriptive, valuable and predictive approach that can assist decision making (Gagliardi, 2002). Sustainability indicators have also been used as a way to improve the information database about the environment, economy and society, to assist in the elaboration of public policies, to simplify studies and reports, and to ensure comparability between different regions (IBGE, 2008; Milanez e Teixeira, 2003).

To reduce the complexity of sustainability assessment, the International Organization for Standardization (ISO) provides globally agreed standards to ensure the quality, safety, and performance of a wide range of smart cities. One can consider that the adherence to smart city standards offers numerous benefits in deploying and managing smart cities while facilitating real-time monitoring performance (The British Standard Institution, 2014). More recently, sustainability indicators were designed to explore the level of sustainable development in urban communities. Those indicators were proposed by the standard (ABNT NBR) "ISO 37120:2017 - Sustainable development of communities - Indicators for city services and quality of life" (ABNT - Associação Brasileira de Normas Técnicas, 2017).

Unfortunately, there are no common units of measure for sustainability indicators, nor are there quantitative criteria for some of their values. Thus, a systemic method based on a reliable scientific methodology, which combines multidimensional components and assesses uncertainties, is necessary. Such a method should be flexible in a way that indicators can be added or removed to obtain a better assessment of the system according to the context (Phillis e Andriantiatsaholiniaina, 2001). For this reason, the use of linguistic values based on a fuzzy logic methodology (MUNDA et al., 1994) seems more appropriate to evaluate sustainability. The following two basic characteristics justify the use of fuzzy logic: (1) it has the ability to deal with complex and polymorphic concepts that are not directly quantifiable and contain ambiguities - moreover, reasoning with such ambiguous concepts may not be clear and obvious, but diffuse; and (2) provides mathematical tools to deal with ambiguous concepts and reasoning, and then provides concrete answers to problems full of subjectivity (since sustainability is, by its means, a subjective concept). What seems unsustainable to an environmentalist may be sustainable for an economist - and the ingredients that mean sustainability may differ for these specialists. There is another important aspect of fuzzy logic: it uses linguistic variables, performing computational analysis with words. If a traditional mathematical approach to sustainability assessment is adopted, such as costbenefit analysis or algebraic formulas, then certain factors - which are impossible to quantify - would be left out. There are also aspects of sustainability that cannot be quantified and still are very important, like values and opinions. In this case, the logic of fuzzy human thinking successfully performs this evaluation (ZADEH, 1973; ZIMMERMANN, 1991).

In this context, this study adapted a model based on Fuzzy Logic to process the indicators proposed by ISO $37120: 2017$, aiming to provide a general score that quantifies and qualifies the level of sustainability of cities. This approach to sustainability has the objective to develop a comprehensive decision support framework that allows smart city managers and investors not only to understand the requirements of their cities, but also to identify their strengths and weaknesses and to develop strategies in response to sustainable development requirements. 


\section{il. Methodology}

\section{a) Data Mining}

We started by collecting data from cities at the "World Council on City Data - WCCD Open City Data Portal" (http://open.dataforcities.org/), to calculate The General Fuzzy Score of a city. This portal "hosts WCCD Global Cities Registry ${ }^{\mathrm{TM}}$ for ISO 37120 and a network of cities committed to improving city services and quality of life with open data" (World Council on City Data - WCCD Open City Data Portal). At WCCD Open City Data Portal, one can find a big number of cities that are, over the time, disclosing their information for a better good. The city data provided by the WCCD is showed through ISO's 37120 Standard indicators, each one of them covering specific areas of sustainable development.

For the purpose of this research, we have chosen (from WCCD Open Data Portal) cities that (1) didn't miss not even one core indicator value and (2) the final calculated Global Score result was or smaller than 30 (poor index) or bigger than 40 (strong index). The four cities that met these criteria were: (a) Tbilisi (GEO),
(b) Guadalajara (MEX),
(c) Boston
(USA) and (d) London (UK).

\section{b) Explaining the (ABNT NBR) ISO 37120:2017 Standard}

Developed by ISO/TC 268 (Technical Committee 268, 2012), the "standardization in the field of Sustainable Cities and Communities will include the development of requirements, frameworks, guidance and supporting techniques and tools related to the achievement of sustainable development considering smartness and resilience, to help all Cities and Communities and their interested parties in both rural and urban areas become more sustainable. The proposed series of International Standards will encourage the development and implementation of holistic and integrated approaches to sustainable development and sustainability" (ISO Technical Committee 268, 2012).

The scope of this Standard, as stated by ISO itself, is: "this standard defines and establishes methodologies for a set of indicators to steer and measure the performance of city services and quality of life. It follows the principles set out and can be used in conjunction with ISO 37101, Sustainable development in communities - Management systems - General principles and requirements, when published, and other strategic frameworks. This Standard is applicable to any city, municipality or local government that undertakes to measure its performance in a comparable and verifiable manner, irrespective of size and location." (ABNT NBR ISO 37120:2017).

To determine the level of sustainability of a city, we have used 46 essential (core) indicators provided by the Brazilian version of the ISO 37120:2017 standard, called "ABNT NBR ISO 37120:2017 - Sustainable development of communities - Indicators for city services and quality of life" (ABNT - Brazilian Association for Technical Standards, 2017) - those indicators equal the International Version of the ISO standard. For the standard, those 46 indicators are "core" ones, what means they are a requirement - there are other indicators that are "supporting" indicators, and even though they have interesting approaches for developing countries cities, they will not be used in this article to minimize the amount of data calculated and analyzed (since they are recommendations only). The used indicators are listed below (this article will use the number described at the ISO Standard to numerate each indicator, when applicable, making them easier to be traced by the reader). A table with "core" requirements and their mathematical equation follows their description (Table 1).

\section{i. Economy Indicators}

- City's unemployment rate: A city's unemployment rate $(C U R)$ shall be calculated as the number of working-age city residents who during the survey reference period were not in paid employment or self-employment, but available for work, and seeking work (CRsw) (numerator) divided by the total labor force (TLF) (denominator). The result shall be multiplied by 100 and expressed as a percentage.

- Assessed value of commercial and industrial properties as a percentage of total assessed value of all properties: The assessed value of commercial and industrial properties (AVcip) as a percentage of total assessed value of all properties shall be expressed as the total assessed value of commercial and industrial properties (TAVcip) (numerator) divided by the total assessed value of all properties (TAVap) (denominator). The result shall then be multiplied by 100 and expressed as a percentage.

- Percentage of city population living in poverty: The percentage of city population living in poverty (PP/p) shall be calculated as the number of people living below the poverty threshold (Pbpt) (numerator) divided by the total current population of the city $(T C P C)$ (denominator). The result shall then be multiplied by 100 and expressed as a percentage.

ii. Education Indicators

- Percentage of female school-aged population enrolled in schools: The percentage of female school-aged population enrolled in schools (FSAPeis) shall be calculated as the number of female school-aged population enrolled at primary and secondary levels in public and private schools

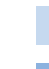


(FSAPps) (numerator) divided by the total number of female school-aged population (TFSAP) (denominator). The result shall then be multiplied by 100 and expressed as a percentage.

- Percentage of students completing primary education: survival rate: The percentage of students completing primary education (SPESr) or survival rate shall be calculated as the total number of students belonging to a school-cohort who complete the final grade of primary education (SCpe) (numerator) divided by the total number of students belonging to a school-cohort, i.e. those originally enrolled in the first grade of primary education (SEfgps) (denominator). The result shall then be multiplied by 100 and expressed as a percentage. The survival rate of primary education shall be expressed as the percentage of a cohort of students enrolled in the first grade of primary education who reached the final grade of primary education.

- Percentage of students completing secondary education: survival rate (core indicator): The percentage of students completing secondary education (SSESr) or survival rate shall be calculated as the total number of students belonging to a school-cohort who complete the final grade of secondary education (SCSe) (numerator) divided by the total number of students belonging to a schoolcohort, i.e. those originally enrolled in the first grade of secondary education (SEfgss) (denominator). The result shall then be multiplied by 100 and expressed as a percentage. The survival rate of secondary education shall be expressed as the percentage of a cohort of students enrolled in the first grade of secondary education who reached the final grade of secondary education;

- Primary education student/teacher ratio (core indicator): The student/teacher ratio (STr) shall be expressed as the number of enrolled primary school students (PSS) (numerator) divided by the number of full-time equivalent primary school classroom teachers (PST) (denominator). The result shall be expressed as the number of students per teacher".

iii. Energy

- Total residential electrical energy use per capita (kWh/year): Total residential electrical energy use per capita (TEUPC) shall be calculated as the total residential electrical usage of a city in kilowatt hours (TEUr) (numerator) divided by the total population of the city (TPOC) (denominator). The result shall be expressed as the total residential electrical use per capita in kilowatt hours/year;

- Percentage of city population with authorized electrical service: The percentage of city population with authorized electrical service (PWAES) shall be calculated as the number of persons in the city with lawful connection to the electrical supply system (PCESS) (numerator) divided by the total population of the city (TPOC) (denominator). The result shall then be multiplied by 100 and expressed as a percentage;

- Energy consumption of public buildings per year $\left(\mathrm{kWh} / \mathrm{m}^{2}\right)$ : Energy consumption of public buildings (ECpb) shall be calculated per year as the total use of electricity at final consumption stage by public buildings (TECpb) (kWh) within a city (numerator) divided by total floor space of these buildings (TFSpb) in square meters $\left(\mathrm{m}^{2}\right)$ (denominator). The result shall be expressed as the total energy consumption of public buildings per year in kilowatt hours per square meter.

- The percentage of total energy derived from renewable sources, as a share of the city's total energy consumption (core indicator): The share of a city's total energy consumption derived from renewable sources (TECrs) shall be calculated as the total consumption of electricity generated from renewable sources (TEGrs) (numerator) divided by total energy consumption (TEC) (denominator). The result shall then be multiplied by 100 and expressed as a percentage. Consumption of renewable sources should include geothermal, solar, wind, hydro, tide and wave energy, and combustibles, such as biomass;

\section{iv. Environment}

- Fine Particulate Matter (PM2.5) concentration: Fine Particulate Matter (PM2.5) concentration (FPMC) shall be calculated as the total mass of collected particles that are 2.5 microns or less in diameter (TCFpm) (numerator) divided by the volume of air sampled (FVAs) (denominator). The result shall be expressed as the concentration of PM2.5 in micrograms per standard cubic meter $\left(\mu \mathrm{g} / \mathrm{m}^{3}\right)$;

- Particulate Matter (PM10) concentration: Particulate Matter (PM10) concentration (PMC) shall be calculated as the total mass of collected particles in the PM10 size range (TCPm) (numerator) divided by the volume of air sampled (PVAs) (denominator). The result shall be expressed as the concentration of PM10 in micrograms per standard cubic meter $\left(\mu \mathrm{g} / \mathrm{m}^{3}\right)$.

- Greenhouse gas emissions measured in tonnes per capita: The greenhouse gas emissions measured in tonnes (GGE) per capita shall be measured as the total amount of greenhouse gases in tonnes (TGG) (equivalent carbon dioxide units) generated over a calendar year by all activities within the city, including indirect emissions outside city boundaries (numerator) divided by the current city population (TPOC) (denominator). The result shall be expressed as the total greenhouse gas emissions per capita in tonnes; 
v. Finance

- Debt service ratio (debt service expenditure as a percentage of a municipality's own-source revenue): Debt service ratio is the ratio $(D S R)$ of debt service expenditures as a per cent of a municipality's ownsource revenue. Debt service ratio shall be calculated as the total long-term debt servicing costs (TLTDSC) including lease payments, temporary financing and other debt charges (numerator) divided by total own- source revenue (CTOR) (denominator). The result shall then be multiplied by 100 and expressed as a percentage of debt service expenditure as a percent of a municipality's own-source revenue.

vi. Fire and Emergency Response

- Number of firefighters per 100000 population: The number of firefighters per 100000 population (TFF) shall be calculated as the total number of paid fulltime firefighters (FTFF) (numerator) divided by one $100000^{\text {th }}$ of the city population (denominator). The result shall be expressed as the number of firefighters per 100000 population.

- Number of fire-related deaths per 100000 population: The number of fire-related deaths per 100000 population (TFD) shall be expressed as the number of deaths directly attributed to a fire incident (DDAfi) with death occurring within 30 days. This indicator shall be calculated as the total number of citizen dfire-related deaths recorded in a 12-month period (numerator), divided by one 100 000th of the city's total population (denominator). The result shall be expressed as the number of fire-related deaths per 100000 population;

- Number of natural disaster-related deaths per 100 000 population: The number of natural disasterrelated deaths (NDrd) per 100000 population shall be expressed as the number of deaths directly attributed to natural disaster incidents (DDAnd). This indicator shall be calculated as the total number of natural disaster-related deaths recorded in a 12month period (numerator), divided by one 100 000th of the city population (denominator). The result shall be expressed as the number of natural disasterrelated deaths per 100000 population.

vii. Governance

- Voter participation in last municipal election (as a percentage of eligible voters): The voter participation in the last municipal election (VPmel) shall be calculated as the number of persons that voted in the last municipal election (NPVme/) (numerator) divided by the city population eligible to vote (ToCPev) (denominator). The result shall then be multiplied by 100 and expressed as a percentage;

- Women as a percentage of total elected to city-level office: The number of women elected to city-level office (WEClO) shall be calculated as the total number of elected city-level positions held by women (TEWclp) (numerator) divided by the total number of elected city-level positions (TEC/p) (denominator). The result shall then be multiplied by 100 and expressed as a percentage;

viii. (12) Health (group of indicators)

- Average life expectancy: The average life expectancy (ALEX) shall be calculated as the average number of years to be lived by a group of people born in the same year, if health and living conditions at the time of their birth remained the same throughout their lives.

- Number of in-patient hospital beds per 100000 population: The number of in-patient hospital beds per 100000 (NipHB) shall be calculated as the total number of in-patient public and private hospital beds (TNipHB) (numerator), divided by one 100 000th of the city's total population (denominator). The result shall be expressed as the number of inpatient public and private hospital beds per 100000 of the city population.

- Number of physicians per 100000 population: The number of physicians per 100000 population (NPH) shall be calculated as the number of general or specialized practitioners whose work-place is in the city (NPHWC) (numerator) divided by one 100 000th of the city's total population (denominator). The result shall be expressed as the number of physicians per 100000 population.

- Under age five mortality per 1000 live births: The underage five mortality per 1000 live births (UA5m) shall refer to the probability of a child born in a specified year dying before reaching the age of five, and shall be expressed as a rate per 1000 live births.

ix. Recreation (non-applicable since there is no core indicator in this group)

x. Safety

- Number of police officers per 100000 population: The number of police officers per 100000 population (NPof) shall be calculated as the number of permanent full-time (or full-time equivalent) sworn police officers (PSPOf) (numerator) divided by one 100 000th of the city's total population (denominator). The result shall be expressed as the number of police officers per 100000 population.

- Number of homicides per 100000 population: The number of homicides per 100000 population (NHmc) shall be calculated as the number of reported homicides (NRHMc) (numerator) divided by one 100 000th of the city's total population (denominator). The result shall be expressed as the number of homicides per 100000 population. 
xi. Shelter

- Percentage of city population living in slums: The percentage of city population living in slums (CPLS) shall be calculated as the number of people living in slums (NPLS) (numerator) divided by the city population (ToCP) (denominator). The result shall then be multiplied by 100 and expressed as a percentage.

xii. Solid Waste

- Percentage of city population with regular solid waste collection (residential): The percentage of city population with regular solid waste collection (CPrsw) shall be calculated as the number of people within the city that are served by solid waste collection (NPCSwC) (numerator) divided by the total city population (TOCP) (denominator). The result shall then be multiplied by 100 and expressed as a percentage.

- Total collected municipal solid waste per capita: The total collected municipal solid waste (TCMsw) per capita shall be expressed as the total municipal solid waste produced in the municipality per person. This indicator shall be calculated as the total amount of solid waste (household and commercial) generated in tonnes (TASWhc) (numerator) divided by the total city population (ToCP) (denominator). The result shall be expressed as total municipal solid waste collected per capita in tonnes.

- Percentage of the city's solid waste that is recycled: The percentage of the city's solid waste that is recycled $(\mathrm{CrSW})$ shall be calculated as the total amount of the city's solid waste that is recycled in tonnes (TCrSW) (numerator) divided by the total amount of solid waste produced in the city in tonnes (TSWpc) (denominator). The result shall then be multiplied by 100 and expressed as a percentage.

xiii. Telecommunications and Innovation

- Number of internet connections per 100000 population: The number of internet connections per 100000 population (NIntC) shall be calculated as the number of internet connections in the city (NIntCc) (numerator) divided by one 100 000th of the city's total population (denominator). The result shall be expressed as the number of internet connections per 100000 population.

- Number of cell phone connections per 100000 population: The number of cell phone connections per 100000 (NoCPC) shall be calculated as the total number of cell phone connections in the city (NoCPCC) (numerator) divided by one 100 000th of the city's total population (denominator). The result shall be expressed as the number of cell phone connections per 100000 population.

- Number of landline phone connections per 100000 population: The number of landline phone connections per 100000 (NoLPC) shall be calculated as the total number of landline telephone connections in the city (NoLPCC) (numerator) divided by one 100 000th of the city's total population (denominator). This result shall be expressed as the number of landline connections per 100000 population.

\section{xiv. Transportation}

- Kilometers of high capacity public transport system per 100000 population: The Kilometers of high capacity public transport system per 100000 population (KHCpts) shall be calculated by adding the Kilometers of high capacity public transport systems operating within the city (KHCptsc) (numerator) divided by one 100 000th of the city's total population (denominator). The result shall be expressed as the Kilometers of high capacity public transport system per 100000 population.

- Kilometers of light passenger public transport system per 100000 population: The Kilometers of light passenger public transport system (KLPpts) per 100000 population shall be calculated by adding the Kilometers of light passenger transport systems provided within the city (KLPptsc) (numerator), divided by one 100 000th of the city's total population (denominator). The result shall be expressed as the Kilometers of light passenger transport system per 100000 population. Expressed as per 100000 population.

- Annual number of public transport trips per capita: Annual number of public transport trips per capita (PTTpc) shall be calculated as the total annual number of transport trips originating in the city (NTToic) - "ridership of public transport" (numerator), divided by the total city population (ToCP) (denominator). The result shall be expressed as the annual number of public transport trips per capita.

- Number of personal automobiles per capita: The number of personal automobiles per capita (PAPC) shall be calculated as the total number of registered personal automobiles in a city (RPAC) (numerator) divided by the total city population (ToCP) (denominator). The result shall be expressed as the number of personal automobiles per capita.

xv. Urban Planning

- Green area (hectares) per 100000 population: Green area (hectares) per 100000 population (GEHct) shall be calculated as the total area (in hectares) of green in the city (TAGC) (numerator) divided by one 100 000th of the city's total population (denominator). The result shall be expressed in hectares of green area per 100000 population.

xvi. Wastewater

- Percentage of city population served by wastewater collection: Percentage of city population served by 
wastewater collection (PSWWc) shall be calculated as the number of people within the city that are served by wastewater collection (PSWWcic) (numerator) divided by the city population (TOCP) (denominator). The result shall then be multiplied by 100 and expressed as a percentage.

- Percentage of the city's wastewater that has received no treatment: Percentage of the city's wastewater that has received no treatment (PWWnt) shall be calculated as the total amount of the city's wastewater that has undergone no treatment (TWWnt) (numerator) divided by the total amount of wastewater produced in the city and collected (TWWPC) (denominator). This result shall then be multiplied by 100 and expressed as a percentage.

- Percentage of the city's wastewater receiving primary treatment: The percentage of the city's wastewater receiving primary treatment ( $P W W p t)$ shall be calculated as the total amount of the city's wastewater that has undergone primary treatment (TWWpt) (numerator) divided by the total amount of wastewater produced in the city and collected (TWWPC) (denominator). This result is then multiplied by 100 and expressed as a percentage of the city's wastewater receiving primary treatment.

- Percentage of the city's wastewater receiving secondary treatment: Percentage of the city's wastewater receiving secondary treatment (PWWst) shall be calculated as the total amount of the city's wastewater that has undergone secondary treatment (TWWst) (numerator) divided by the total amount of wastewater produced in the city and collected (TWWPC) (denominator). The result shall then be multiplied by 100 and expressed as a percentage.

- Percentage of the city's wastewater receiving tertiary treatment: Percentage of the city's wastewater receiving tertiary treatment (PWWtt) shall be calculated as the total amount of the city's wastewater that has undergone tertiary treatment (TWWtt) (numerator) divided by the total amount of wastewater produced in the city and collected (TWWPC) (denominator). The result shall then be multiplied by 100 and expressed as a percentage;

xvii. Water and Sanitation

- Percentage of city population with potable water supply service: The percentage of city population with potable water supply service (PPWs) shall be calculated as the total number of people with potable water supply service (TPPWs) (numerator) divided by total city population (TOCP) (denominator). The result shall then be multiplied by 100 and expressed as a percentage of city population serviced by a potable water supply service.

- Percentage of city population with sustainable access to an improved water source: The percentage of city population with sustainable access to an improved water source (PSAiws) shall be calculated as the total population with access to an improved water source (TPAiws) (numerator) divided by the total city population (ToCP) (denominator). The result shall then be multiplied by 100 and expressed as a percentage.

- Percentage of population with access to improved sanitation: The percentage of population with access to improved sanitation (PAAis) shall be calculated as the total number of people using improved sanitation facilities (TPAis) (numerator) divided by the total city population (TOCP) (denominator). The result shall then be multiplied by 100 and expressed as a percentage.

- Total domestic water consumption per capita (liters/day): The total domestic water consumption per capita (TDWCC) shall be calculated as the total amount of the city's water consumption in liters per day for domestic use (TDWC) (numerator) divided by the total city population (TOCP) (denominator). The result shall be expressed as the total domestic water consumption per capita in liters per day.

Table 1: ISO 37120 Standard's Core Indicators and its Equations

\begin{tabular}{|c|c|}
\hline (ISO's Indicator Number) Indicator & Equation \\
\hline (5.1) City's unemployment rate & $\mathrm{Q} 5.1=\mathrm{CRU}=\mathrm{CRswTLF} \times 100$ \\
\hline $\begin{array}{l}\text { (5.2) Assessed value of commercial and industrial properties as a percentage } \\
\text { of total assessed value of all properties }\end{array}$ & Q5.2=AVcip= TAVcipTAVap $\times 100$ \\
\hline (5.3) Percentage of city population living in poverty & $\mathrm{Q} 5.3=\mathrm{PPlp}=\mathrm{PbptTCPc} \times 100$ \\
\hline (6.1) Percentage of female school-aged population enrolled in schools & Q6.1 $=$ FSAPeis $=$ FSAPpsTFSAP $\times 100$ \\
\hline (6.2) Percentage of students completing primary education: survival rate & Q6.2=SPEsr $=$ SCpeSEfgps $\times 100$ \\
\hline (6.3) Percentage of students completing secondary education: survival rate & Q6.3 $=$ SSEsr $=$ SCseSEfgss $\times 100$ \\
\hline (6.4) Primary education student/teacher ratio & Q6.4=STr= PSSPST \\
\hline (7.1) Total residential electrical energy use per capita (kWh/year) & Q7.1=TEUpc $=$ TEUrTPoC \\
\hline (7.2) Percentage of city population with authorized electrical service & Q7.2=PWAES $=$ PCEssTPoC $\times 100$ \\
\hline (7.3) Energy consumption of public buildings per year $\left(\mathrm{kWh} / \mathrm{m}^{2}\right)$ & Q7.3 $=E C p b=$ TECpbTFSpb \\
\hline $\begin{array}{l}\text { (7.4) The percentage of total energy derived from renewable sources, as a } \\
\text { share of the city's total energy consumption }\end{array}$ & Q7.4=ECpb $=$ TECrsTEC \\
\hline (8.1) Fine Particulate Matter (PM2.5) concentration & Q8.1=FPMc $=$ TCFpmFVAs \\
\hline
\end{tabular}


(8.2) Particulate Matter (PM10) concentration

(8.3) Greenhouse gas emissions measured in tonnes per capita

(9.1) Debt service ratio (debt service expenditure as a percentage of a municipality's own-source revenue)

(10.1) Number of firefighters per 100000 population

(10.2) Number of fire-related deaths per 100000 population

(10.3) Number of natural disaster-related deaths per 100000 population

(11.1) Voter participation in last municipal election (as a percentage of eligible voters)

(11.2) Women as a percentage of total elected to city-level office

(12.1) Average life expectancy

(12.2) Number of in-patient hospital beds per 100000 population

(12.3) Number of physicians per 100000 population

(12.4) Under age five mortality per 1000 live births

(14.1) Number of police officers per 100000 population

(14.2) Number of homicides per 100000 population

(15.1) Percentage of city population living in slums

(16.1) Percentage of city population with regular solid waste collection (residential)

(16.2) Total collected municipal solid waste per capita

(16.3) Percentage of the city's solid waste that is recycled

(17.1) Number of internet connections per 100000 population

(17.2) Number of cell phone connections per 100000 population

(18.1) Kilometers of high capacity public transport system per 100000 population

(18.2) Kilometers of light passenger public transport system per 100000 population

(18.3) Annual number of public transport trips per capita

(18.4) Number of personal automobiles per capita

(19.1) Green area (hectares) per 100000 population

(20.1) Percentage of city population served by wastewater collection

(20.2) Percentage of the city's wastewater that has received no treatment

(20.3) Percentage of the city's wastewater receiving primary treatment

(20.4) Percentage of the city's wastewater receiving secondary treatment

(20.5) Percentage of the city's wastewater receiving tertiary treatment

(21.1) Percentage of city population with potable water supply service

(21.2) Percentage of city population with sustainable access to an improved water source

(21.3) Percentage of population with access to improved sanitation

(21.4) Total domestic water consumption per capita (liters/day)
Q8.2 $=$ PMc $=$ TCpmPVAs

Q8.3=TGGE $=$ TGGTPOC

Q9.1=DSR $=$ TLTDscCTOR $\times 100$

Q10.1=TGGE $=$ TGGTPoC100 000

$\mathrm{Q} 10.2=\mathrm{TFD}=$ DDAfiTPoC100 000

Q10.3=NDrd = DDAndTPoC100 000

Q11.1 =VPmel $=$ NPVmelToCPev $\times 100$

Q11.2 $=$ WEclo $=$ TEWclpTEclp $\times 100$

N/A

Q12.2 $=$ NipHB $=$ TNipHBTPoC100 000

$\mathrm{Q} 12.3=\mathrm{NPH}=\mathrm{NPH} w \mathrm{wP} T \mathrm{C} 100000$

N/A

Q14.1 $=$ NPof $=$ PSPofTPoC100 000

$\mathrm{Q} 14.2=\mathrm{NHmc}=\mathrm{NRHmcTPoC} 100000$

$\mathrm{Q} 15.1=\mathrm{CPLS}=\mathrm{NPLSTOCP} \times 100$

$\mathrm{Q} 16.1=\mathrm{CPrsw}=\mathrm{NPC}$ swcToCP $\times 100$

$\mathrm{Q} 16.2=\mathrm{TCMsw}=\mathrm{TASWhcToCP}$

$\mathrm{Q} 16.3=\mathrm{CrSW}=\mathrm{TCrSWTSW} p \mathrm{x} 100$

Q17.1 $=$ NIntC $=$ NIntCcTPoC100 000

$\mathrm{Q} 17.2=\mathrm{NoCPC}=$ NoCPCcTPoC100 000

$\mathrm{Q} 18.1=\mathrm{KHCpts}=\mathrm{KHCptscTPoC100000}$

Q18.2=KLPpts $=$ KLPptscTPoC100 000

$\mathrm{Q}$ 18.3 $=\mathrm{PTT} p \mathrm{p}=$ NTToicToCP

$\mathrm{Q} 18.4=\mathrm{PAPC}=\mathrm{RPACTOCP}$

Q19.1 = GEHct $=$ TAGcTPoC100 000

$\mathrm{Q} 20.1=\mathrm{PSWWC}=\mathrm{PSWW}$ cicToCP $\times 100$

Q20.2 $=$ PWWnt $=$ TWWntTWWpc $\times 100$

Q20.3 $=$ PWWpt $=$ TWWptTWWpc $\times 100$

Q20.4=PWWst $=$ TWWstTWWpc $\times 100$

$\mathrm{Q} 20.5=\mathrm{PWWtt}=\mathrm{TWWttTW}$ pc $\times 100$

Q21.1 $=$ PPWs $=$ TPPWsToCP $\times 100$

Q21.2 $=$ PSAiws $=$ TPAiwsToCP $\times 100$

Q21.3 $=$ PAAis $=$ TPAisToCP $\times 100$

Q21.4=TDWCc $=$ TDWCToCP
On the next table (Table 2) there are all core indicators values of the chosen cities to test the model. As mentioned, all the information has been collected

from WCCD, and was the latest available at the Portal by the time of this article writing.

\section{Table 2: City Core Indicator's Values collected from WWCD Open Data Portal}

\begin{tabular}{|c|c|c|c|c|}
\hline Indicator & Tbilisi & Guadalajara & Boston & London \\
\hline Economy & & & & \\
\hline City's unemployment rate & $21.38 \%$ & $3.75 \%$ & $3.37 \%$ & $5.99 \%$ \\
\hline $\begin{array}{l}\text { Assessed value of commercial and industrial properties as a } \\
\text { percentage of total assessed value of all properties }\end{array}$ & $20.02 \%$ & $34.02 \%$ & $31.00 \%$ & $16.15 \%$ \\
\hline Percentage of city population living in poverty & $11.10 \%$ & $36.26 \%$ & $20.99 \%$ & $25.77 \%$ \\
\hline Education & & & & \\
\hline $\begin{array}{l}\text { Percentage of female school-aged population enrolled in } \\
\text { schools }\end{array}$ & $101.31 \%$ & $91.08 \%$ & $96.90 \%$ & $98.17 \%$ \\
\hline $\begin{array}{l}\text { Percentage of students completing primary education: survival } \\
\text { rate }\end{array}$ & $95.23 \%$ & $96.79 \%$ & $100.00 \%$ & $100.00 \%$ \\
\hline $\begin{array}{l}\text { Percentage of students completing secondary education: } \\
\text { survival rate }\end{array}$ & $73.85 \%$ & $85.86 \%$ & $76.00 \%$ & $101.59 \%$ \\
\hline Primary education student/teacher ratio & 66.48 & 30.00 & 14.50 & 20.87 \\
\hline
\end{tabular}




\begin{tabular}{|c|c|c|c|c|}
\hline $\begin{array}{l}\text { Energy } \\
\text { Total residential electrical energy use per capita ( } \mathrm{kWh} / \mathrm{year}) \\
\text { Percentage of city population with authorized electrical service } \\
\text { Energy consumption of public buildings per year }\left(\mathrm{kWh} / \mathrm{m}^{2}\right) \\
\text { The percentage of total energy derived from renewable sources, } \\
\text { as a share of the city's total energy consumption }\end{array}$ & $\begin{array}{c}878.07 \\
100.00 \% \\
19.49 \\
19.32 \%\end{array}$ & $\begin{array}{r}355.73 \\
99.59 \% \\
137.67 \\
15.41 \%\end{array}$ & $\begin{array}{c}1,971.00 \\
100.00 \% \\
110.60 \\
15.00 \%\end{array}$ & $\begin{array}{c}1,556.70 \\
100.00 \% \\
172.00 \\
2.03 \%\end{array}$ \\
\hline $\begin{array}{l}\text { Environment } \\
\text { Fine Particulate Matter (PM2.5) concentration } \\
\text { Particulate Matter (PM10) concentration } \\
\text { Greenhouse gas emissions measured in tonnes per capita }\end{array}$ & $\begin{array}{c}26.30 \\
49.30 \\
3.03 \\
\end{array}$ & $\begin{array}{c}21.26 \\
43.98 \\
3.27 \\
\end{array}$ & $\begin{array}{c}6.51 \\
12.53 \\
9.60 \\
\end{array}$ & $\begin{array}{c}14.20 \\
19.30 \\
4.89 \\
\end{array}$ \\
\hline $\begin{array}{l}\text { Finance } \\
\text { Debt service ratio (debt service expenditure as a } \\
\text { percentage of a municipality's own-source revenue) }\end{array}$ & $1.96 \%$ & $86.63 \%$ & $6.40 \%$ & $7.52 \%$ \\
\hline $\begin{array}{l}\text { Fire \& Emergency } \\
\text { Number of firefighters per } 100000 \text { population } \\
\text { Number of fire-related deaths per } 100000 \text { population } \\
\text { Number of natural disaster-related deaths per } 100 \quad 000 \\
\text { population }\end{array}$ & $\begin{array}{c}61.81 \\
1.35 \\
1.98\end{array}$ & $\begin{array}{l}22.5 \\
0.06 \\
0.00\end{array}$ & $\begin{array}{c}220.4 \\
0.76 \\
0.00\end{array}$ & $\begin{array}{c}59.85 \\
0.34 \\
0.00\end{array}$ \\
\hline $\begin{array}{l}\text { Governance } \\
\text { Voter participation in last municipal election (as a percentage of } \\
\text { eligible voters) } \\
\text { Women as a percentage of total elected to city-level office }\end{array}$ & $\begin{array}{l}37.04 \% \\
24.00 \% \\
\end{array}$ & $\begin{array}{l}50.00 \% \\
41.98 \% \\
\end{array}$ & $\begin{array}{l}13.63 \% \\
28.60 \% \\
\end{array}$ & $\begin{array}{l}38.65 \% \\
30.77 \%\end{array}$ \\
\hline $\begin{array}{l}\text { Health } \\
\text { Average life expectancy } \\
\text { Number of in-patient hospital beds per } 100000 \text { population } \\
\text { Number of physicians per } 100000 \text { population } \\
\text { Under age five mortality per } 1000 \text { live births }\end{array}$ & $\begin{array}{l}72.90 \\
664.78 \\
1,405.66 \\
9.20\end{array}$ & $\begin{array}{c}75.70 \\
97.30 \\
219.72 \\
17.60 \\
\end{array}$ & $\begin{array}{l}80.00 \\
894.86 \\
1,153.32 \\
5.68\end{array}$ & $\begin{array}{c}82.05 \\
266.80 \\
279.30 \\
4.37\end{array}$ \\
\hline $\begin{array}{l}\text { Safety } \\
\text { Number of police officers per } 100000 \text { population } \\
\text { Number of homicides per } 100000 \text { population }\end{array}$ & $\begin{array}{c}156.96 \\
4.13\end{array}$ & $\begin{array}{c}137.18 \\
16.11\end{array}$ & $\begin{array}{c}324.10 \\
6.69\end{array}$ & $\begin{array}{c}371.94 \\
1.14\end{array}$ \\
\hline $\begin{array}{c}\text { Shelter } \\
\text { Percentage of city population living in slums }\end{array}$ & $1.17 \%$ & $7.26 \%$ & $0.52 \%$ & $0.35 \%$ \\
\hline $\begin{array}{l}\text { Solid Waste } \\
\text { Percentage of city population with regular solid waste collection } \\
\text { (residential) } \\
\text { Total collected municipal solid waste per capita } \\
\text { Percentage of the city's solid waste that is recycled }\end{array}$ & $\begin{array}{c}100.00 \% \\
0.35 \\
0.00 \%\end{array}$ & $\begin{array}{c}99.01 \% \\
0.36 \\
8.00 \%\end{array}$ & $\begin{array}{c}100.00 \% \\
0.32 \\
20.70 \%\end{array}$ & $\begin{array}{c}100.00 \% \\
0.43 \\
30.56 \%\end{array}$ \\
\hline $\begin{array}{l}\text { Telecom \& Innovation } \\
\text { Number of internet connections per } 100000 \text { population } \\
\text { Number of cell phone connections per } 100000 \text { population }\end{array}$ & $\begin{array}{c}29,161.99 \\
133,029.83 \\
\end{array}$ & $\begin{array}{r}12,086.00 \\
100,002.51 \\
\end{array}$ & $\begin{array}{r}72,423.18 \\
185,401.14 \\
\end{array}$ & $\begin{array}{r}32,164.00 \\
139,170.98 \\
\end{array}$ \\
\hline $\begin{array}{l}\text { Transportation } \\
\text { Kilometers of high capacity public transport system per } 100000 \\
\text { population } \\
\text { Kilometers of light passenger public transport system per } 100 \\
000 \text { population } \\
\text { Annual number of public transport trips per capita } \\
\text { Number of personal automobiles per capita }\end{array}$ & $\begin{array}{c}401.35 \\
327.31 \\
0.47\end{array}$ & $\begin{array}{c}263.63 \\
29.30^{\star} \\
0.30\end{array}$ & $\begin{array}{c}78.49 \\
404.46 \\
0.27\end{array}$ & $\begin{array}{c}14.10 \\
49.29 \\
563.03 \\
0.30\end{array}$ \\
\hline $\begin{array}{c}\text { Urban Planning } \\
\text { Green area (hectares) per } 100000 \text { population }\end{array}$ & $1,306.78$ & 18.05 & 241.96 & 871.89 \\
\hline $\begin{array}{l}\text { Wastewater } \\
\text { Percentage of city population served by wastewater collection } \\
\text { Percentage of the city's wastewater that has received no } \\
\text { treatment } \\
\text { Percentage of the city's wastewater receiving primary treatment } \\
\text { Percentage of the city's wastewater receiving secondary } \\
\text { treatment } \\
\text { Percentage of the city's wastewater receiving tertiary treatment }\end{array}$ & $\begin{array}{r}85.87 \% \\
0.00 \% \\
100.00 \% \\
100.00 \% \\
0.00 \%\end{array}$ & $\begin{array}{r}98.67 \% \\
45.76 \% \\
54.24 \% \\
40.40 \% \\
13.84 \%\end{array}$ & $\begin{array}{c}100.00 \% \\
0.00 \% \\
100.00 \% \\
100.00 \% \\
100.00 \%\end{array}$ & $\begin{array}{c}100.00 \% \\
0.00 \% \\
100.00 \% \\
100.00 \% \\
100.00 \%\end{array}$ \\
\hline
\end{tabular}




\section{Water And Sanitation}

Percentage of city population with potable water supply service Percentage of city population with sustainable access to an improved water source

Percentage of population with access to improved sanitation

Total domestic water consumption per capita (liters/day)

\section{c) SAFE Model}

Developed by Yannis A. Phillis and Luc A. Andriantiatsaholiniaina (2011) in their article "Sustainability: an ill-defined concept and its assessment using fuzzy logic", the SAFE (Sustainability Assessment by Fuzzy Evaluation) model "provides a mechanism for measuring development sustainability".

As informed by the authors: (1) The output of the model

$\approx$ is a degree (\%) of sustainability of the system under examination (locality, state, country, etc.); (2) The model is open to new inputs as reality and experience change, and it weighs all inputs according to their impact; (3) It should be stressed that this method in itself is both a new definition and numerical assessment of

\begin{tabular}{|l|c|c|c}
\hline $93.22 \%$ & $97.98 \%$ & $100.00 \%$ & $100.00 \%$ \\
\hline $93.22 \%$ & $98.29 \%$ & $100.00 \%$ & $100.00 \%$ \\
\hline $87.57 \%$ & $85.33 \%$ & $99.48 \%$ & $100.00 \%$ \\
317.15 & 202.68 & 144.66 & 164.41 \\
\hline
\end{tabular}

sustainability. The two main differences between the SAFE model and the adapted SAFE model we are using are: (a) the indicators used in our model are different from SAFE, and (b) we have simplified the number of fuzzy variables, making more feasible for cities from developing countries to analyze their data. The SAFE model has been chosen because of its flexibility and applicability, and even though we foresee its feasibility, we decided to reduce some layers of the model, "creating" a simpler configuration to address the less complete and advanced data from developing countries cities. The adapted SAFE model can be graphically understood through Figure 1.

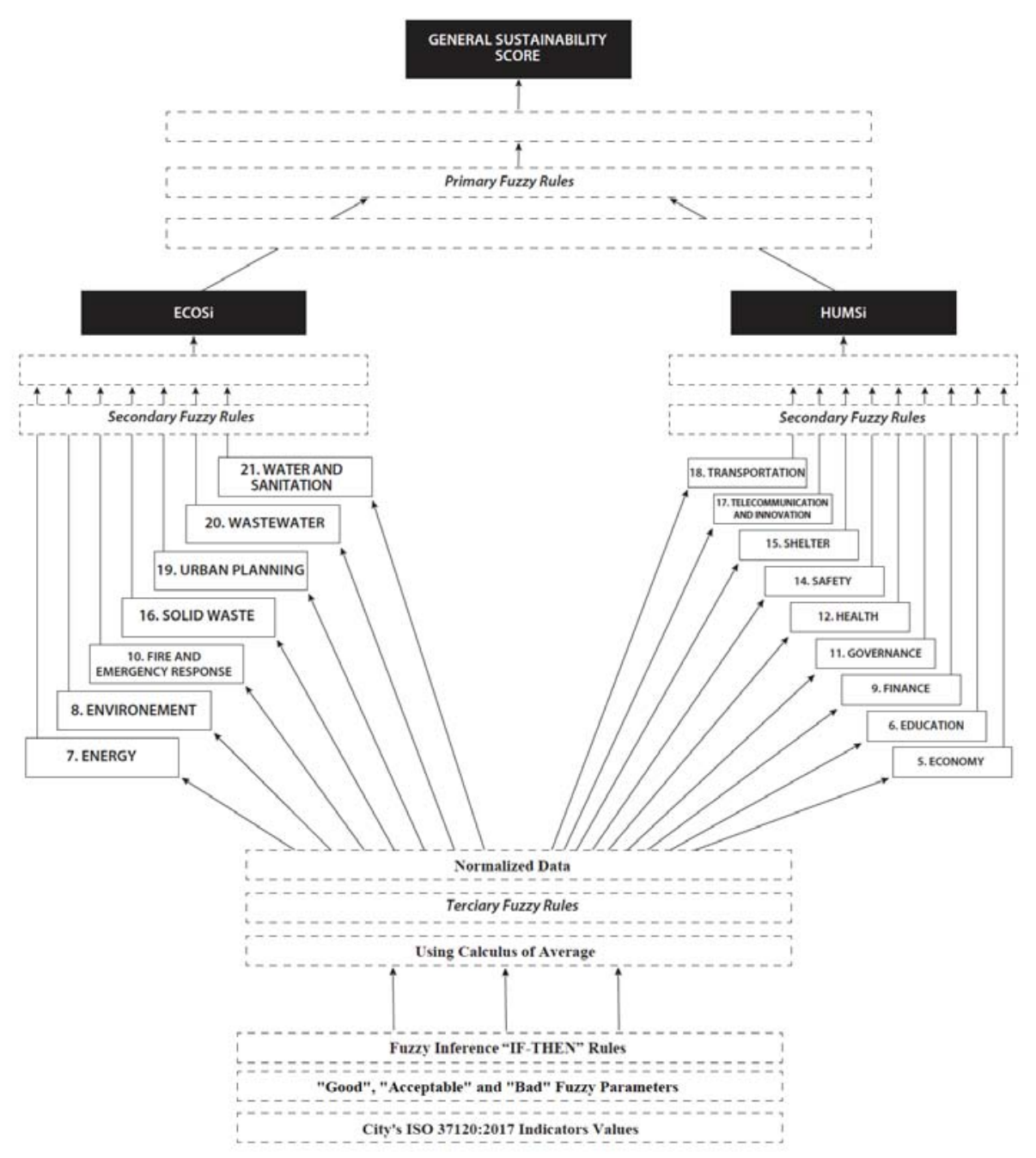

Fig. 1: Methodology for SAFE Model Adapted to Support ISO 37120 Indicators 


\section{i. Fuzzy Rules used in the Model}

At the 'Tertiary Fuzzy Rules' we have established three ranges of fuzzy parameters (Table 3) to be used with each indicator value: "GOOD", "ACCEPTABLE" and "BAD". Those parameters intervals have been estimated through observation by specialists in each kind of indicator, based on the data collected from WCCD Open Data Portal - fuzzy logic uses expert knowledge to define linguistic variables and rules (Phillis e Andrian-tiatsaholiniaina, 2001).

After running the Fuzzy Logic for each group of indicators - i.e. from 5 (Economy) to 21 (Water and Sanitation) -, the "defuzzification" of each group result was treated through 'Secondary Fuzzy Rules', when we normalized the data in a scale from 0 to 100, being 0 to 29.9 (BAD), 30 to 59.9 (ACCEPTABLE) and 60 to 100 (GOOD).
After that, we have got two Fuzzy value 'groups': HUMSi (for the Human- related variables) and ECOSi (for the Ecological related variables). Those results have been "defuzzified" and then treated through 'Primary Fuzzy Rules' to get the "General Sustainability Score";

HUMSi encompasses these groups of indicators: Economy, Education, Finance, Governance, Shelter, Health, Safety, Telecommunications and Innovation and Transportation;

ECOSi encompasses these groups of indicators: Energy, Environment, Fire and Emergency Response, Solid Waste, Urban Planning and Water and Sanitation;

\section{Table 3: Fuzzy parameters for each ISO 37.120 Indicator}

\begin{tabular}{|c|c|c|c|}
\hline Indicator & \multicolumn{3}{|c|}{ Fuzzy Parameter } \\
\hline $\begin{array}{l}\text { City's unemployment rate } \\
\text { Assessed value of commercial and industrial properties as a percentage of } \\
\text { total assessed value of all properties } \\
\text { Percentage of city population living in poverty }\end{array}$ & $\begin{array}{l}\text { GOOD } \\
0-5 \\
>40 \\
0-20\end{array}$ & $\begin{array}{l}\text { ACCEPTABLE } \\
>5 \leq 10 \\
>20 \leq 40 \\
>20 \leq 40\end{array}$ & $\begin{array}{l}\text { BAD } \\
>10 \\
0-20 \\
>40\end{array}$ \\
\hline $\begin{array}{l}\text { Education } \\
\text { Percentage of female school-aged population enrolled in schools } \\
\text { Percentage of students completing primary education: survival rate } \\
\text { Percentage of students completing secondary education: survival rate } \\
\text { Primary education student/teacher ratio }\end{array}$ & $\begin{array}{l}>80 \\
>80 \\
>60 \\
0-20\end{array}$ & $\begin{array}{l}>50 \leq 80 \\
>50 \leq 80 \\
>30 \leq 60 \\
>20 \leq 30\end{array}$ & $\begin{array}{l}0-50 \\
0-50 \\
0-30 \\
>30\end{array}$ \\
\hline $\begin{array}{l}\text { Energy } \\
\text { Total residential electrical energy use per capita }(\mathrm{kWh} / \mathrm{year}) \\
\text { Percentage of city population with authorized electrical service } \\
\text { Energy consumption of public buildings per year }\left(\mathrm{kWh} / \mathrm{m}^{2}\right) \\
\text { The percentage of total energy derived from renewable sources, as a share of } \\
\text { the city's total energy consumption }\end{array}$ & $\begin{array}{l}>1000 \\
>90 \\
>200 \\
>40\end{array}$ & $\begin{aligned}>500 & \leq 1000 \\
>80 & \leq 90 \\
>100 & \leq 200 \\
>20 & \leq 40\end{aligned}$ & $\begin{array}{l}0-500 \\
0-80 \\
0-100 \\
0-20\end{array}$ \\
\hline $\begin{array}{l}\text { Environment } \\
\text { Fine Particulate Matter (PM2.5) concentration } \\
\text { Particulate Matter (PM10) concentration } \\
\text { Greenhouse gas emissions measured in tonnes per capita }\end{array}$ & $\begin{array}{l}0-10 \\
0-25 \\
0-8\end{array}$ & $\begin{array}{c}>10 \leq 20 \\
>25 \leq 50 \\
>8 \leq 12\end{array}$ & $\begin{array}{l}>20 \\
>50 \\
>12\end{array}$ \\
\hline $\begin{array}{l}\text { Finance } \\
\text { Debt service ratio (debt service expenditure as a percentage of a } \\
\text { municipality's own-source revenue) }\end{array}$ & $0-20$ & $>20 \leq 50$ & $>50$ \\
\hline $\begin{array}{l}\text { Fire \& Emergency } \\
\text { Number of firefighters per } 100000 \text { population } \\
\text { Number of fire-related deaths per } 100000 \text { population } \\
\text { Number of natural disaster-related deaths per } 100000 \text { population }\end{array}$ & $\begin{array}{l}>40 \\
0-0,5 \\
0-0,5\end{array}$ & $\begin{array}{l}>20 \leq 40 \\
>0,5 \leq 1 \\
>0,5 \leq 1\end{array}$ & $\begin{array}{l}0-20 \\
>1 \\
>1\end{array}$ \\
\hline $\begin{array}{l}\text { Governance } \\
\text { Voter participation inlast municipal election (as a percentage of eligible voters) } \\
\text { Women as a percentage of total elected to city-level office }\end{array}$ & $\begin{array}{l}>70 \\
>50\end{array}$ & $\begin{array}{l}>50 \leq 70 \\
>30 \leq 50\end{array}$ & $\begin{array}{l}0-50 \\
0-30\end{array}$ \\
\hline $\begin{array}{l}\text { Health } \\
\text { Average life expectancy } \\
\text { Number of in-patient hospial beds per } 100000 \text { population } \\
\text { Number of physicians per } 100000 \text { population } \\
\text { Under age five mortality per } 1000 \text { live births }\end{array}$ & $\begin{array}{l}>80 \\
>300 \\
>200 \\
0-5\end{array}$ & $\begin{aligned}>70 & \leq 80 \\
>200 & \leq 300 \\
>100 & \leq 200 \\
>100 & \leq 200\end{aligned}$ & $\begin{array}{l}0-70 \\
0-200 \\
0-100 \\
0-100\end{array}$ \\
\hline
\end{tabular}




\begin{tabular}{|c|c|c|c|}
\hline $\begin{array}{l}\text { Safety } \\
\text { Number of police officers per } 100000 \text { population } \\
\text { Number of homicides per } 100000 \text { population }\end{array}$ & $\begin{array}{l}>200 \\
0-5\end{array}$ & $\begin{array}{l}>100 \leq 200 \\
>5 \leq 10\end{array}$ & $\begin{array}{l}0-100 \\
>10\end{array}$ \\
\hline $\begin{array}{l}\text { Shelter } \\
\text { Percentage of city population living in slums }\end{array}$ & $0-5$ & $>5 \leq 10$ & $>10$ \\
\hline Solid Waste & $>95$ & $>90 \leq 95$ & $0-90$ \\
\hline $\begin{array}{l}\text { Percentage of city population with regular solid waste collection (residential) } \\
\text { Total collected municipal solid waste per capita } \\
\text { Percentage of the city's solid waste that is recycled }\end{array}$ & $\begin{array}{l}>0,3 \\
>50\end{array}$ & $\begin{aligned}>0,15 & \leq 0,3 \\
> & 30 \leq 50\end{aligned}$ & $\begin{array}{l}0-0,15 \\
0-30\end{array}$ \\
\hline $\begin{array}{l}\text { Telecom. \& Innov. } \\
\text { Number of internet connections per } 100000 \text { population } \\
\text { Number of cell phone connections per } 100000 \text { population }\end{array}$ & $\begin{array}{r}>20000 \\
>100000\end{array}$ & $\begin{array}{l}>10000 \leq 20000 \\
>80000 \leq 100000\end{array}$ & $\begin{array}{l}0-10000 \\
0-80000\end{array}$ \\
\hline $\begin{array}{l}\text { Transportation } \\
\text { Kilometers of high capacity public transport system per } 100000 \text { population } \\
\text { Kilometers of light passenger public transport system per } 100000 \text { population } \\
\text { Annual number of public transport trips per capita } \\
\text { Number of personal automobiles per capita }\end{array}$ & $\begin{array}{l}>14 \\
>200 \\
>400 \\
0-0,25\end{array}$ & $\begin{aligned}> & 7 \leq 14 \\
> & 100 \leq 200 \\
> & 200 \leq 400 \\
> & 0,25 \leq 0,4\end{aligned}$ & $\begin{array}{l}0-7 \\
0-100 \\
0-200 \\
>0,4\end{array}$ \\
\hline $\begin{array}{c}\text { Urban Planning } \\
\text { Green area (hectares) per } 100000 \text { population }\end{array}$ & $>200$ & $>100 \leq 200$ & $0-100$ \\
\hline $\begin{array}{l}\text { Wastewater } \\
\text { Percentage of city population served by wastewater collection } \\
\text { Percentage of the city's wastewater that has received no treatment } \\
\text { Percentage of the city's wastewater receiving primary treatment } \\
\text { Percentage of the city's wastewater receiving secondary treatment } \\
\text { Percentage of the city's wastewater receiving tertiary treatment }\end{array}$ & 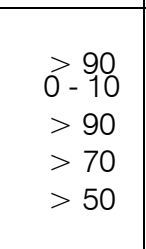 & $\begin{array}{l}>80 \leq 90 \\
>10 \leq 20 \\
>70 \leq 90 \\
>50 \leq 70 \\
>30 \leq 50\end{array}$ & $\begin{array}{l}0-80 \\
>20 \\
0-70 \\
0-50 \\
0-30\end{array}$ \\
\hline $\begin{array}{l}\text { Water \& Sanitation } \\
\text { Percentage of city population with potable water supply service } \\
\text { Percentage of city population with sustainable access to an improved wate } \\
\text { source } \\
\text { Percentage of population with access to improved sanitation } \\
\text { Total domestic water consumption per capita (liters/day) }\end{array}$ & $\begin{array}{l}>95 \\
>95 \\
>95 \\
> \\
>200\end{array}$ & $\begin{array}{l}>90 \leq 95 \\
>90 \leq 95 \\
>90 \leq 95 \\
>150 \leq 200\end{array}$ & $\begin{array}{l}0-90 \\
0-90 \\
0-90 \\
0-150\end{array}$ \\
\hline
\end{tabular}

\section{ii. Fuzzy Calculi}

To calculate data using the adapted SAFE Model logic, we have developed an algorithm in Python language (https://www.python.org/) under Anaconda Python Data Science Platform (https://www. anaconda. com). We decided to do this, instead of using ready-touse mathematical platforms, for the flexibility we have gained on the way of adding more variables and rules in the future. We also have used Scikit-fuzzy library (https://github.com/scikit-fuzzy/scikit-fuzzy) with Python for the fuzzy logic process (Python, Anaconda, Github and Scikit are trademarks of their owners).

Fuzzy equations were not described in this article, since there is plenty of literature on the subject in any case, to have a deep view of the equations, you can refer to Yannis et al. (2011).

\section{iii. Graph}

The adapted SAFE Model calculi will generate graphics that can be interpreted this way (Fig 2):

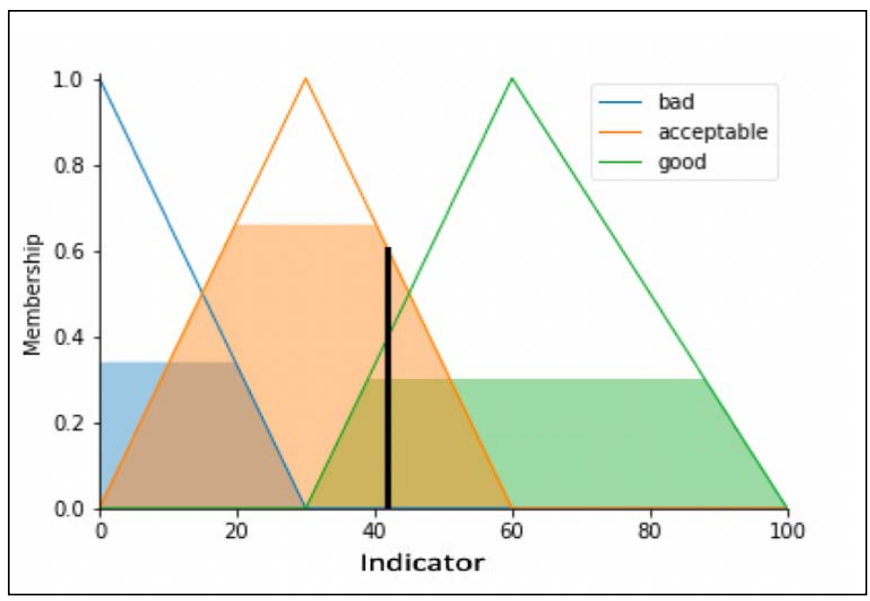

Fig. 2: Fuzzy output graph for a given group of indicators 
- $\quad$ The first triangle (from left to right) shows the fuzzy "BAD" range;

- $\quad$ The second triangle (from left to right) shows the fuzzy "ACCEPTABLE" range;

- $\quad$ The third triangle (from left to right) shows the fuzzy "GOOD" range;

- The height of the solid area in the first triangle shows "how bad" the Indicator is;

- The height of the solid area in the second triangle shows "how acceptable" the Indicator is;

- The height of the solid area in the third triangle shows "how good" the Indicator is;

- The black vertical line shows the actual CRISP Value (calculated numeric value resulting from the defuzzification process) of the group of indicators;
- The height of the black vertical line shows how relevant (to the overall fuzzy result) the crisp value is.

\section{RESULTS}

Through the adapted SAFE Model Fuzzy calculi, we have been able to determine a global score number, at the end of the fuzzy rules, that can be seen in the next table (Table 4).

- To Tbilisi, the calculated general score was: 26.4882

- To Guadalajara, the calculated general score was: 26.4584

- To Boston, the calculated general score was: 47.1025

- To London, the calculated general score was: 47.0857

Table 4: SAFE Model Calculi Results

\begin{tabular}{|c|c|c|c|c|}
\hline & $\begin{array}{l}\text { Tbilisi } \\
\text { (GEO) }\end{array}$ & Guadalajara (MEX) & $\begin{array}{l}\text { Boston } \\
\text { (USA) }\end{array}$ & $\begin{array}{l}\text { London } \\
\text { (UK) }\end{array}$ \\
\hline Indicator & \multicolumn{4}{|l|}{ HUMSi } \\
\hline 5 Economy & 27.2329 & 54.2042 & 33.0121 & 42.5339 \\
\hline 6. Education & 30.0279 & 46.2247 & 54.1088 & 50.8832 \\
\hline 9. Finance & 59.6755 & 13.0576 & 53.3368 & 51.9278 \\
\hline 11.Governance & 40.9456 & 46.9240 & 47.7288 & 40.4772 \\
\hline 15. Shelter & 55.6007 & 27.0628 & 59.4777 & 60.6362 \\
\hline 12. Health & 39.3827 & 10.0341 & 37.6115 & 47.5721 \\
\hline 14. Safety & 26.5344 & 47.9997 & 38.4643 & 20.4454 \\
\hline 17. Telco \& Innovation & 45.5658 & 47.5484 & 43.1992 & 45.3375 \\
\hline 18. Transportation & 47.5852 & 47.3632 & 48.2151 & 47.8583 \\
\hline Calculated HUMSi: & 29.9590 & 29.9604 & 51.7908 & 52.4961 \\
\hline Indicator & \multicolumn{4}{|c|}{ ECOSi } \\
\hline 7. Energy & 27.0407 & 26.1312 & 26.0261 & 15.6583 \\
\hline 8. Environment & 44.4931 & 44.6521 & 42.8161 & 45.9163 \\
\hline 10. Fire \& Emergency & 47.4968 & 36.8213 & 63.6628 & 63.3044 \\
\hline 16. Solid Waste & 9.9686 & 21.6357 & 28.6053 & 31.7512 \\
\hline 19. Urban Planning & 63.3363 & 18.9522 & 63.2986 & 63.3130 \\
\hline 20. Wastewater & 9.9686 & 25.7874 & 64.7161 & 64.7161 \\
\hline 21. Water \& Sanitation & 53.1570 & 63.2986 & 29.9483 & 36.7871 \\
\hline Calculated ECOSi: & 48.4515 & 48.5864 & 47.0019 & 49.6479 \\
\hline Calculated General Score & 26.4882 & 26.4584 & 47.1025 & 47.0857 \\
\hline
\end{tabular}

Those calculi have generated graphics, as the one explained on Figure 2, that show the degree of membership of each crisp value (for each indicator). On the next table (Table 5) you will find all ISO 37120 indicators with their fuzzy number and graphic calculated. You will also find the tertiary, secondary and primary fuzzy rules (described on figure 1), all depicted on graphics - those graphics are disposed in columns (that determine the city) and lines (that determine the indicator). At line 22 of Table 5, you will finally find the global score for each city. 
Table 5: Adapted SAFE Model fuzzy calculi graphic results for each city

\begin{tabular}{|c|c|c|c|c|}
\hline CITY: & TBILISI & GUADALAJARA & BOSTON & LONDON \\
\hline $\begin{array}{c}\text { INDICATO } \\
\text { R }\end{array}$ & $\mathrm{A}$ & $\mathrm{B}$ & $\mathrm{C}$ & $\mathrm{D}$ \\
\hline
\end{tabular}

$\frac{2}{8}$

2 Education

年

3 Finance
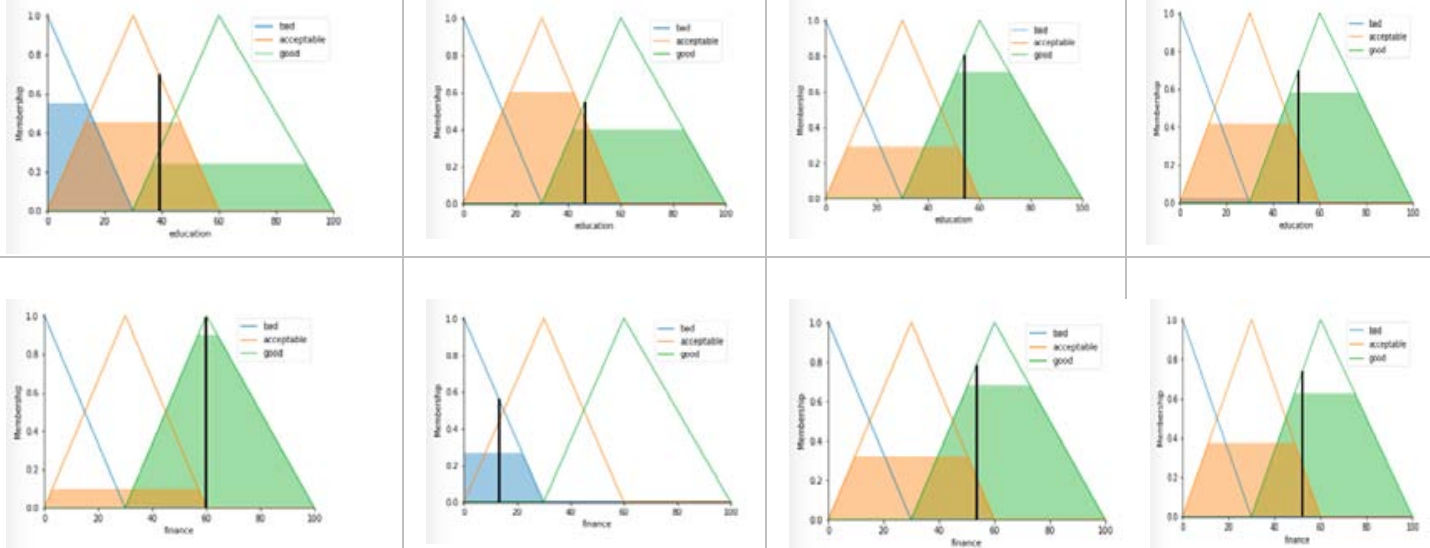

4 Governanc
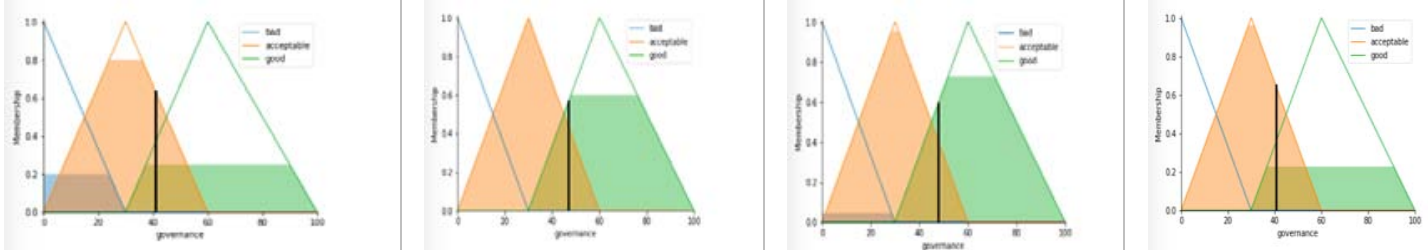

5 Shelter
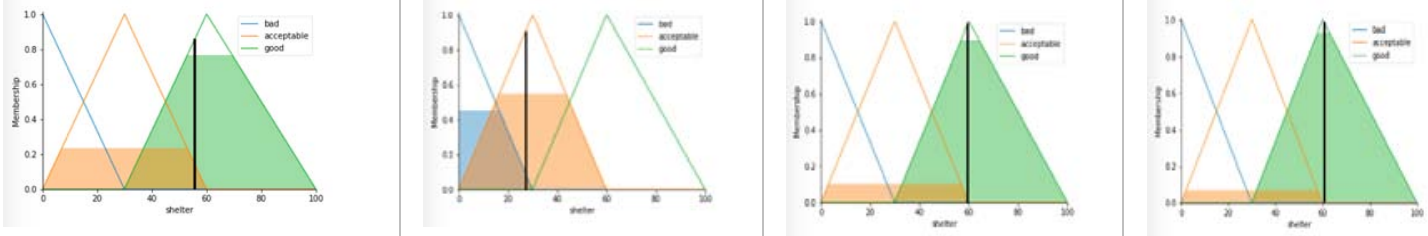

\section{Health}
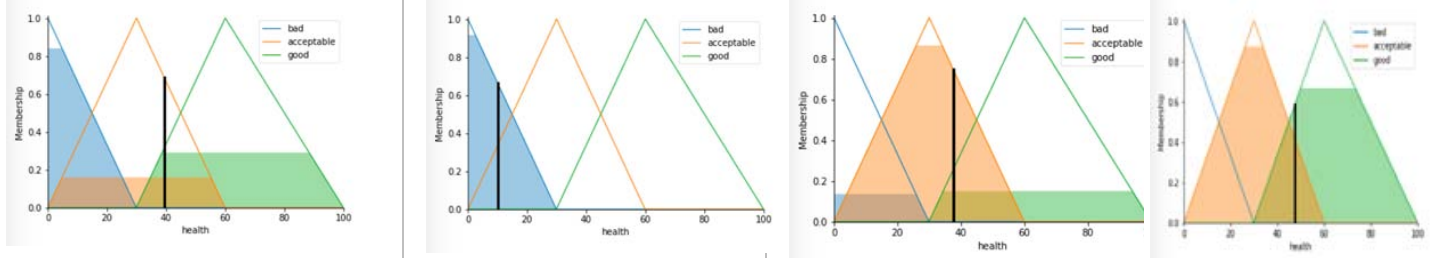

7 Safety
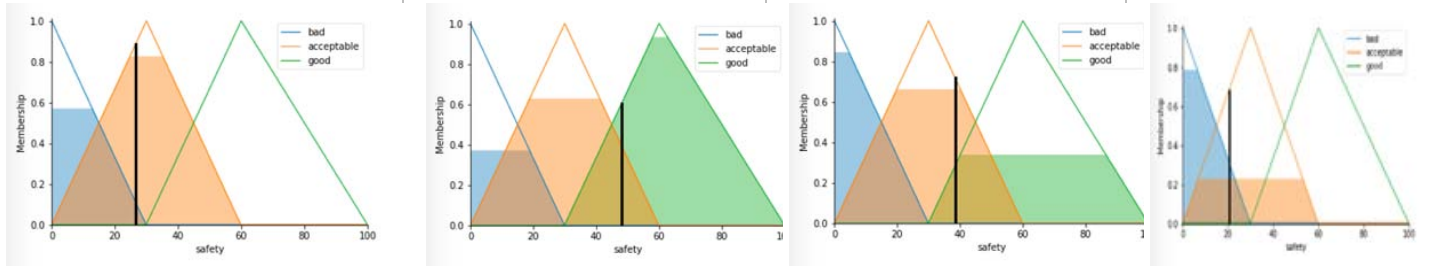


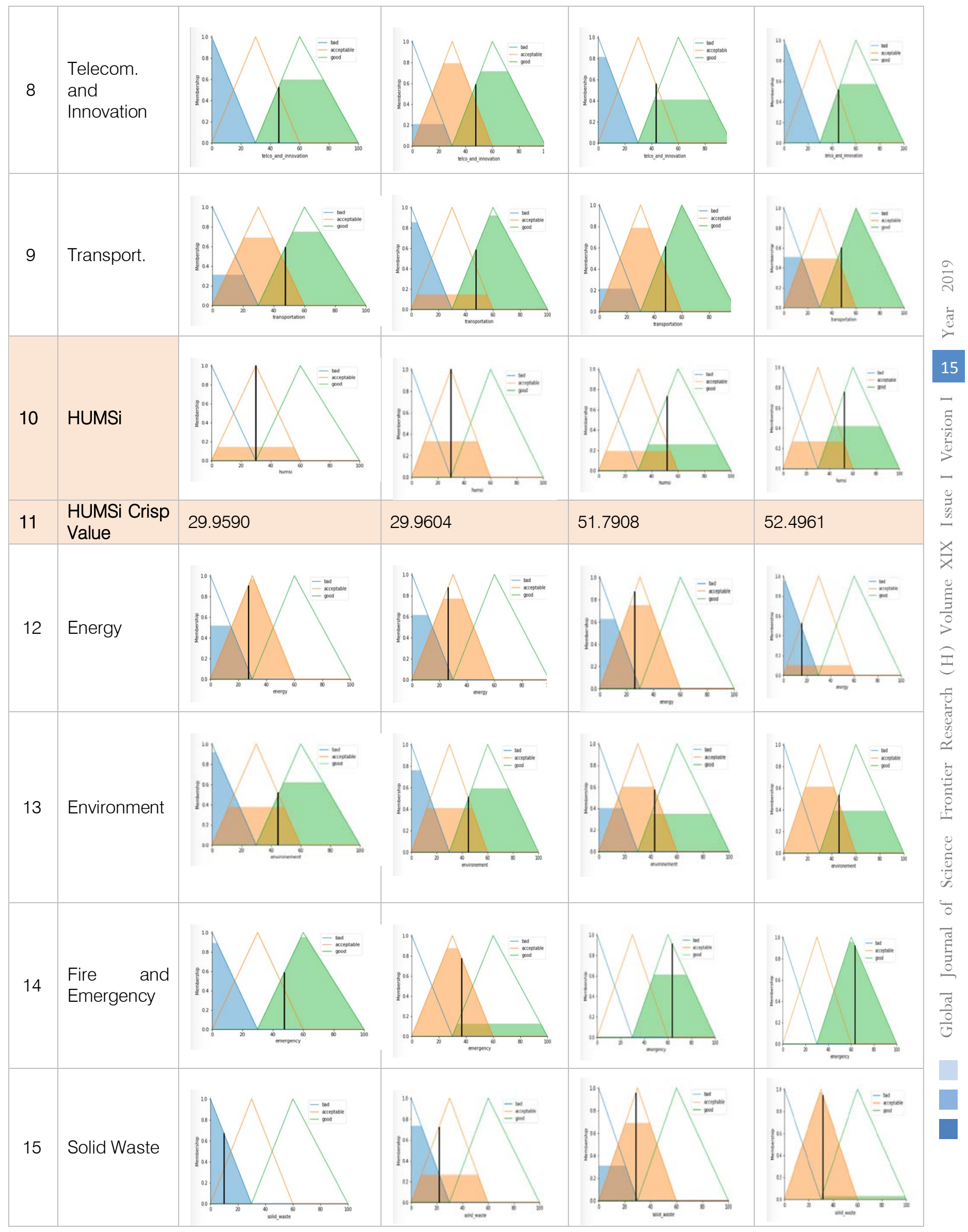




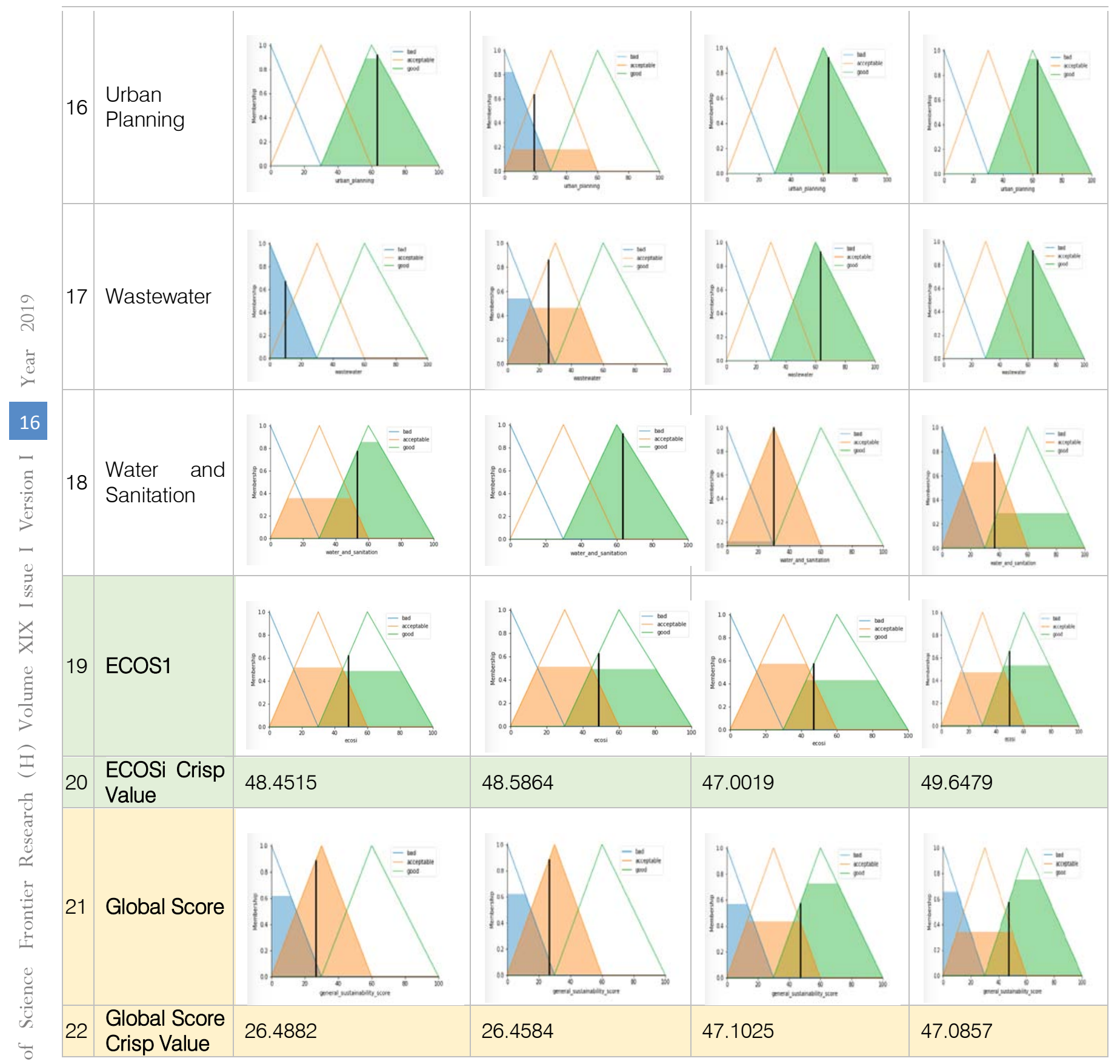

a) Table 5 Results Explanation

In Table 5 (above) we have:

- City of Tbilisi (GEO) at column A

- City of Guadalajara (MEX) at column B

- City of Boston (USA) at column C

- $\quad$ City of London (UK) at column D

- Indicators are listed at the Table's lines.

Adapted SAFE Model Fuzzy result of Economy indicator(s) (for the four cities):

- Tbilisi has a numeric score of 27.2329, with a high membership degree at ACCEPTABLE, and a relatively high membership degree at BAD (Graph A1);
- Guadalajara has a numeric score of 54.2042, with a high membership degree at GOOD, and a medium membership degree at ACCEPTABLE (Graph B1);

- Boston has a numeric score of 33.0121, with a very high membership degree at ACCEPTABLE, and a very low membership degree at GOOD (Graph C1);

- London has a numeric score of 42.5339, with a high membership degree at ACCEPTABLE, and a medium membership degree at GOOD (Graph D1);

Adapted SAFE Model Fuzzy result of Education indicator(s) (for the four cities):

- Tbilisi has a numeric score of 39.0279, with a high membership degree at BAD, relatively high 
membership degree at ACCEPTABLE and a relatively low membership degree at GOOD (Graph A2);

- $\quad$ Guadalajara has a numeric score of 46.2247, with a high membership degree at ACCEPTABLE, and a medium membership degree at GOOD (Graph B2);

- Boston has a numeric score of 54.1088 , with a very high membership degree at GOOD, and a medium membership degree at ACCEPTABLE (Graph C2);

- London has a numeric score of 50.8832, with a relatively high membership degree at GOOD, and a medium membership degree at ACCEPTABLE (Graph D2);

Adapted SAFE Model Fuzzy result of Finance indicator(s) (for the four cities):

- $\quad$ Tbilisi has a numeric score of 59.6755, with a very high membership degree at GOOD and a relatively low membership degree at ACCEPTABLE (Graph A3);

- Guadalajara has a numeric score of 13.0756, with a medium membership degree at BAD (Graph B3);

- Boston has a numeric score of 53.3368, with a high membership degree at GOOD, and a medium membership degree at ACCEPTABLE (Graph C3);

- $\quad$ London has a numeric score of 51.9278, with a high membership degree at GOOD, and a medium membership degree at ACCEPTABLE (Graph D3);

Adapted SAFE Model Fuzzy result of Governance indicator(s) (for the four cities):

- $\quad$ Tbilisi has a numeric score of 40.9456, with a very high membership degree at ACCEPTABLE and a low membership degree at BAD and GOOD (Graph A4);

- Guadalajara has a numeric score of 46.9240, with a very high membership degree at ACCEPTABLE and a high membership degree at GOOD (Graph B4);

- Boston has a numeric score of 47.7288 , with a very high membership degree at ACCEPTABLE, and also a high membership degree at GOOD and a slightest membership degree at BAD (Graph C4);

- London has a numeric score of 40.4772, with a very high membership degree at ACCEPTABLE, and a low membership degree at GOOD (Graph D4);

Adapted SAFE Model Fuzzy result of Shelter indicator(s) (for the four cities):

- $\quad$ Tbilisi has a numeric score of 55.6007, with a very high membership degree at GOOD and a low membership degree at ACCEPTABLE (Graph A5);

- Guadalajara has a numeric score of 27.0628, with a high membership degree at ACCEPTABLE and a relatively high membership degree at BAD (Graph B5);
- Boston has a numeric score of 59.4777 , with a high membership degree at GOOD, and a low membership degree at ACCEPTABLE (Graph C5);

- $\quad$ London has a numeric score of 60.6362, with a very high membership degree at GOOD, and a very low membership degree at ACCEPTABLE (Graph D5);

Adapted SAFE Model Fuzzy result of Health indicator(s) (for the four cities)

- $\quad$ Tbilisi has a numeric score of 39.3827, with a very high membership degree at BAD and a low membership degree at GOOD and an even lower membership degree at ACCEPTABLE (Graph A6);

- Guadalajara has a numeric score of 10.0341, with a very high membership degree at BAD (Graph B6);

- $\quad$ Boston has a numeric score of 37.6115, with a high membership degree at ACCEPTABLE, and a low membership degree at GOOD and BAD (Graph C6);

- London has a numeric score of 47.5721, with a very high membership degree at ACCEPTABLE, and a high membership degree at GOOD (Graph D6);

Adapted SAFE Model Fuzzy result of Safety indicator(s) (for the four cities):

- $\quad$ Tbilisi has a numeric score of 26.5344, with a high membership degree at ACCEPTABLE, and an almost as high membership degree at BAD (Graph A7);

- $\quad$ Guadalajara has a numeric score of 47.9997, with a very high membership degree at GOOD, an almost as high membership degree at ACCEPTABLE and a medium membership degree at BAD (Graph B7);

- $\quad$ Boston has a numeric score of 38.4643, with a high membership degree at BAD, an almost as high membership degree at ACCEPTABLE, and a medium membership degree at GOOD (Graph C7);

- $\quad$ London has a numeric score of 20.4454, with a very high membership degree at BAD, and a medium to low membership degree at ACCEPTABLE (Graph D7);

Adapted SAFE Model Fuzzy result of Telecommunication and Innovation indicator(s) (for the four cities)

- $\quad$ Tbilisi has a numeric score of 45.5658, with a very high membership degree at BAD and a high membership degree at GOOD (Graph A8);

- Guadalajara has a numeric score of 47.5484, with a very high membership degree at ACCEPTABLE, an almost as high membership degree at GOOD, and a low membership degree at BAD (Graph B8);

- $\quad$ Boston has a numeric score at 43.1992, with a high membership degree at BAD and a medium membership degree at GOOD (Graph C8); 
- London has a numeric score of 45.3375 , with a very high membership degree at BAD and a high membership degree at GOOD (Graph D8);

Adapted SAFE Model Fuzzy result of Transportation indicator(s) (for the four cities):

- Tbilisi has a numeric score of 47.5852 , with a high membership degree at GOOD, an almost as high membership degree at ACCEPTABLE, and a medium membership degree at BAD (Graph A9);

- Guadalajara has a numeric score of 47.3632, with a very high membership degree at $B A D$, a very high membership degree at GOOD, and a low membership degree at ACCEPTABLE (Graph B9);

- Boston has a numeric score of 48.2151, with a very high membership degree at GOOD, a high membership degree at ACCEPTABLE, and a low to medium membership degree at BAD (Graph C9);

- London has a numeric score of 47.8583, with a very high membership degree at GOOD, a medium membership degree at ACCEPTABLE and at BAD (Graph D9);

Adapted SAFE Model Fuzzy result of HUMSi group of indicators (for the four cities):

- For Tbilisi, HUMSi has received a score of 29.9590, with a concentration of its membership degree at ACCEPTABLE, on a low level (Graph A10). It means the Human group of indicators has provided the information that they are in a level of acceptance, but still in a low condition.

- For Guadalajara, HUMSi has received a score of 29.9604 , with a concentration of its membership degree at ACCEPTABLE on a low level (slightest bigger than Tbilisi) (Graph B10). It means the Human group of indicators has provided the information that they are in a level of acceptance, but still in a low condition.

- For Boston, HUMSi has received a score of 51.7908 , with a concentration of its membership degree at ACCEPTABLE and GOOD, on a low to medium level (GOOD slightest bigger ACCEPTABLE) (Graph C10). It means the Human group of indicators has provided the information that they are in a level of acceptance but already evolved to a good position;

- For London, HUMSi has received a score of 52.4961, with a concentration of its membership degree at ACCEPTABLE and GOOD, on a medium to high level (GOOD bigger than ACCEPTABLE) (Graph D10). It means the adapted fuzzy calculi for the "human" group of indicators has provided the information that the city has acceptable characteristics, but already evolved very much to a good position;
Adapted SAFE Model Fuzzy result of Energy indicator(s) (for the four cities):

- Tbilisi has a numeric score of 27.0407, with a very high membership degree at ACCEPTABLE and a medium to high membership degree at BAD (Graph A12);

- Guadalajara has a numeric score of 26.1312, with a high membership degree at ACCEPTABLE and an almost as high membership degree at BAD (Graph B12);

- Boston has a numeric score of 26.0261, with a high membership degree at ACCEPTABLE and an almost as high membership degree at BAD (Graph C12);

- London has a numeric score of 15.6583, with a very high membership degree at BAD, and a very low membership degree at ACCEPTABLE (Graph D12);

Adapted SAFE Model Fuzzy result of Environment indicator(s) (for the four cities)

- Tbilisi has a numeric score of 44.4931, with a very high membership degree at BAD, a medium to high membership degree at GOOD, and a medium membership degree at ACCEPTABLE (Graph A13);

- Guadalajara has a numeric score of 44.6521, with a high membership degree at BAD, a medium to high membership degree at GOOD, and a medium membership degree at ACCEPTABLE (Graph B13);

- Boston has a numeric score of 42.8161 , with a medium membership degree at BAD, a medium to high membership degree at ACCEPTABLE, and a medium membership degree at GOOD (Graph C13);

- London has a numeric score of 45.9163 , with a medium to high membership degree at ACCEPTABLE, a medium membership degree at GOOD (Graph D13);

Adapted SAFE Model Fuzzy result of Fire and Emergency Response indicator(s) (for the four cities):

- Tbilisi has a numeric score of 47.4968 , with a very high membership degree at BAD and a very high membership degree at GOOD (Graph A14);

- Guadalajara has a numeric score of 36.8213, with a high membership degree at BAD, a medium to high membership degree at GOOD, and a medium membership degree at ACCEPTABLE (Graph B14);

- Boston has a numeric score of 63.6628 , with a medium membership degree at BAD, a medium to high membership degree at ACCEPTABLE, and a medium membership degree at GOOD (Graph C14);

- London has a numeric score of 63.3044 , with a medium to high membership degree at ACCEPTABLE, a medium membership degree at GOOD (Graph D14); 
Adapted SAFE Model Fuzzy result of Solid Waste indicator(s) (for the four cities):

- Tbilisi has a numeric score of 9.9686, with a very high membership degree at BAD only (Graph A15);

- Guadalajara has a numeric score of 21.6357, with a high membership degree at BAD and a medium membership degree at ACCEPTABLE (Graph B15);

- Boston has a numeric score of 28.6053 , with a medium to high membership degree at ACCEPTABLE, and an almost medium membership degree at BAD (Graph C15);

- London has a numeric score of 31.7512, with a very high membership degree at ACCEPTABLE, a very low membership degree at GOOD (Graph D15);

Adapted SAFE Model Fuzzy result of Urban Planning indicator(s) (for the four cities):

- Tbilisi has a numeric score of 63.3363, with a high membership degree at GOOD only (Graph A16);

- Guadalajara has a numeric score of 18.9522, with a high membership degree at BAD and a low membership degree at ACCEPTABLE (Graph B16);

- Boston has a numeric score of 63.2986, with a very high membership degree at GOOD only (Graph C16);

- London has a numeric score of 63.3130, with a very high membership degree at GOOD only (Graph D16);

Adapted SAFE Model Fuzzy result of Wastewater indicator(s) (for the four cities

- Tbilisi has a numeric score of 9.9686, with a very high membership degree at BAD only (Graph A17);

- Guadalajara has a numeric score of 25.7874, with a medium to high membership degree at BAD and a medium membership degree at ACCEPTABLE (Graph B17);

- Boston has a numeric score of 64.7161, with a very high membership degree at GOOD (Graph C17);

- London has a numeric score of 64.7161, with a very high membership degree at GOOD (Graph D17);

Adapted SAFE Model Fuzzy result of Water and Sanitation indicator(s) (for the four cities):

- Tbilisi has a numeric score of 53.1570, with a high membership degree at GOOD and a medium membership degree at ACCEPTABLE (Graph A18);

- Guadalajara has a numeric score of 63.2986, with a very high membership degree at GOOD only (Graph B18);

- Boston has a numeric score of 29.9483, with a very high membership degree at ACCEPTABLE and a very low membership degree at BAD (Graph C18);

- London has a numeric score of 36.7871, with a very high membership degree at BAD, a high membership degree at ACCEPTABLE and a medium to low membership degree at GOOD (Graph D18);
Adapted SAFE Model Fuzzy result of ECOSi group of indicators (for the four cities):

- $\quad$ For Tbilisi, ECOSi has received a score of 48.4515 (A20), with a concentration of its membership degree at ACCEPTABLE and GOOD, on a medium to high level (Graph A19). It means the Ecological group of indicators has provided the information that they are in a level of acceptance, but already evolved to a good position.

- For Guadalajara, ECOSi has received a score of 48.5864 (B20), with a concentration of its membership degree at ACCEPTABLE and GOOD, on a medium to high level (Graph B19). It means the Ecological group of indicators has provided the information that they are in a level of acceptance, but already evolved to a good position.

- For Boston, ECOSi has received a score of 47.0019 (C20), with a concentration of its membership degree at ACCEPTABLE and GOOD, on a medium to high level (Graph C19) - ACCEPTABLE is greater than GOOD. It means the Ecological group of indicators has provided the information that they are in a level of acceptance, but already evolved to a good position.

- $\quad$ For London, ECOSi has received a score of 49.6479 (D20), with a concentration of its membership degree at ACCEPTABLE and GOOD, on a medium to high level (Graph D19) - GOOD is greater than ACCEPTABLE. It means the adapted fuzzy calculuscalculi for the "ecological" group of indicators has provided the information that the city has acceptable characteristics, but already evolved very much to a good position;

Adapted SAFE Model Fuzzy result of GENERAL SCORE (GE) (for the four 4 cities)

- For Tbilisi, GE has received a score of 26.4882 (A22), with a concentration of its membership degree at ACCEPTABLE (on a low to medium level), and with a relatively high membership degree at BAD (Graph A21). It means the city has an overall acceptable condition, but still has bad numbers regarding its ISO 37120 Standard indicators.

- For Guadalajara, GE has received a score of 26.4584 (B22), with a concentration of its membership degree at ACCEPTABLE (on a low to medium level), and with a relatively high membership degree at BAD (Graph B21). It means the city has an overall acceptable condition, but still has bad numbers regarding its ISO 37120 Standard indicators.

- For Boston, GE has received a score of 47.1025 (C22), with a high membership degree at GOOD, a medium membership degree at ACCEPTABLE, and a medium to high membership degree at $B A D$ (Graph C21). It means the city has an overall good 
condition with acceptable characteristics, but still has bad numbers regarding its ISO 37120 Standard indicators.

- For London, ECOSi has received a score of 47.0857 (D22), with a high membership degree at GOOD, a medium membership degree at ACCEPTABLE, and a medium to high membership degree at BAD (Graph D21). It means the city has an overall good condition with acceptable characteristics, but still has bad numbers regarding its ISO 37120 Standard indicators.

\section{Discussion}

Living organisms need food, water and oxygen to be converted in energy. This energy can then be used on things like walking, breathing, communicating and thinking. This process, however, creates residues that are disposed on the environment - this is a normal living organism metabolism synthesis (Science for Environment Policy, 2016). Following the same line of thought, cities also have their metabolism, i.e., they need water, raw material and processes to generate energy, providing the necessary means to its inhabitants and, at the end, generating residues too (Kennedy et al., 2007). Urban population will overpass $68 \%$ of total global population by 2050 (UN, 2014) what, together with the accelerating consume industry (to create economic development), can leverage the destruction of the environment, offering risks to economic activities and to the population health (Albino et al., 2015) - the balance between resources usage, energy generation and the posterior release of residues, is a very worrisome issue on this unbridled urban growth. Because of these issues, questions related to the way cities organize themselves have been taking place on discussions all over, trying to make them (the cities) more sustainable and more intelligent (Bulkeley and Betsill, 2005; European Commission, 2014; Giffinger and Haindl, 2007). Because of this, cities all around the globe are starting to show interest for sustainability, thinking of how develop themselves without surpassing biosphere regeneration's capacity (Carretero, 2002; Goodland and Daly, 1996; Hiremath et al., 2013; Holden et al., 2017).

The sustainability notion came through when risk to the environment has been noticed, because of the development a new social, economic and urban paradigm. The concept has become internationally spread out at the end of the 80's, followed by a wide adoption of strategies and speeches related to the theme (Elias and Krogstie, 2017). Since then, the most accepted idea of sustainable development is that "humanity has the ability to make development sustainable to ensure that it meets the needs of the present without compromising the ability of future generations to meet their own needs" (WECD, 1987). However, this classical definition has been misinterpreted and misused, what made it receive a lot of critics. As a result, the sustainable development idea has become widely multifaceted, contested and many times has been interpreted as contradictory and oxymoronic (Hopwoodil et al., 2005; Jacobs, 1999; Jöst, 2002; Munda, 1997; Murcott, 1997; Redclift, 1987, 2005). The absence of a more universal definition for sustainable development has given origin to multiple interpretations and philosophical arguments, what inevitably lead to an explosion of social and economic indicators (Bibri and Krogstie, 2017).

Recently the discussion is taking another path: how sustainability can be reached with the help of "intelligence", that is, with technology and connectivity, bringing all urban systems together (Albino et al., 2017)? From new approaches of the city, information, initiatives and investments create actions towards the evolution of those urban systems, and as a way of controlling and measuring those incentives (and their results, of course), rankings have been created, being made of indicators that measured the performance of an object in a specific attribute (Meijering et al., 2014). Those rankings have exploded in quantity, with the objective of indicate best cities on each chapter (theme) and describe their strengths and weaknesses. Yet, as much alike as they can be, each one of the ranks carry an evaluation method, varying dimensions, indicators and weighs (for the indicators), what creates an unbalance between the ranked cities (Giffinger and Haindl, 2007).

Also, there isn't also a unique definition for "smart city" - only divergent points of view (and if you change the word smart for digital, for example, those points leverage). Regarding Albino (2015), the term intelligent city was firstly used on the 90's and had ICT (information and communication technology) as its main argument or requirement to consider a city "smart" - this vision, however, had been criticized for suggesting big investments on the information transmission, what has favored big players from the market. The concepts and definitions about smart cities have been evolving and gathering more space and dimensions to make cities more "circular", sustainable, popular and connected. An intelligent city incorporates infrastructure to facilitate mobility, adds effectivity on its main sectors, saves energy, improves and preserves air and water quality, identifies problems and fixes them promptly, besides so many other qualities. Those operations are always guided by interoperability between connected sectors and systems (Kanter and Litow, 2009).

A sustainable urban community should understand the connections between economy and environment - it should promote equity, social inclusion, be economically productive, have their buildings in 
harmony with nature, retain historical roots, and be preserved by all generations. On the other side, an unsustainable community uses all its resources faster than they can be renewed and generates more residues than the natural system can deal with (Rai, 2012). Regarding the sustainable intelligent cities, the evaluation of sustainability is widely used to support decision making processes on urban planning and development. Those processes need reliable tools and methodologies to show, evaluate and enhance the progress of their sustainability goals (Bibri and Krogstie, 2017), so multiple indicators to measure quality of life have appeared on the year 2000 (Mercer 2014). It is important to highlight again that the explosion of indicators came from the great of interpretations of 'sustainable development', and the different approaches for its operationalization. However, urban sustainability indicators were created by companies from the environment consultancy, capitalism, research and green citizenship organizations (Ahvenniemi et al., 2017; McManus, 2012). Thus, the tools of urban sustainability assessment were developed from a 'top-down' perspective by specialized organizations. However, several scholars (Berardi, 2013, Robinson and Cole, 2015, Turcu, 2013) advocate the integration of citizenled, participatory and localized approaches. This is grounded in the underlying assumption that relationships among urban dwellers, their activities and the environment, should be better understood to achieve the level of sustainability required in terms of integrating their dimensions. The sustainability indicators should then be used by public administration and policy makers to confirm whether cities should implement development strategies, allowing the evaluation and monitoring of urban activities (Tanguay et al., 2010). Bottom line, evaluation performance tools are intended to classify sustainable cities or to enable cities to find best practices and compare best solutions (Ahvenniemi et al., 2017).

One of the challenges of building sustainable development is to create measurement instruments capable of providing information that facilitates the assessment of the degree of sustainability of societies, monitors the trends of their development and helps in the definition of improvement goals. Sustainability indicators have also been used as a way to improve the information based on the environment, to assist in the elaboration of public policies, to simplify studies and reports and to ensure comparability between different regions (Milanez and Teixeira, 2003). Working with sustainability indicators can help to seeing the links between different aspects of development within the various levels at which they coexist, and to appreciate the complex interaction between their various dimensions (OECD, 2006). Like any other management tool, the indicators have some technical limitations. Most indicators related to sustainability do not have a single conceptual system; they measure the approximation of reality, not reality precisely (Van Bellen, 2005). Also, inadequate selection of indicators leads to a deficient, often ambiguous, and therefore politically manipulating system or 'produced' or 'instituted' interpretations of reality. Therefore, before using them, it is recommended to point out the complementary aspect of the indicators: their reading and interpretation must be followed by a thorough analysis of the phenomenon in question (Kayano and Caldas, 2002).

ISO 37120 is part of a new series of international standards currently under development and "offers a holistic and integrated approach to sustainable development" (ISO, 2018), including indicators of municipal services, quality of life, smart cities and resilient cities, to provide a uniform approach. It helps cities learn from each other, allowing an uniform comparison across a broad range of performance measures, and supports policy development and prioritization. It is applicable to any city, municipality or local government that wants to measure its performance in a comparable and verifiable manner, regardless of size and location (ANSI, 2018). To help cities target and self-assess municipal service performance management and all service provision, ISO 37120 broadly describes 19 sectors and services provided by a city: economy, education, energy, environment, environment and climate change, finance, governance, health, housing, population and social conditions, recreation, safety, solid waste, sport and culture, telecommunications, transportation, urban/local agriculture and food security, urban planning, wastewater and water.

For each one of these, this standard provides an important indicator that should be reported by any user implementing the document. The standard also identifies a profile indicator for each, as well as a variety of support indicators. For example, for economy, the central indicator is the city's unemployment rate. The logic behind the determination is that the unemployment rate is considered one of the most informative indicators of the labor market and reflects the health of the economy as a whole. In this section, the standard describes how to accurately determine this primary indicator (ANSI, 2018). Maintaining, enhancing, and accelerating progress toward improved urban services and quality of life is also central to the definition of smart cities and resilient cities. ISO 37120 should be used in conjunction with two standards currently under development, ISO 37122 and ISO 37123, which will provide indicators to measure progress toward smart cities and resilient cities, respectively (ISO, 2018).

Considering that the different indicators are not homogeneous, it may be required to assign a weight to each indicator to allow aggregation. This assignment can be done through a combination of values that come 
from different judgments and different criteria, using a procedure based on "fuzzy logic" (Gagliardi et al., 2007). The daily natural language consists of being indefinite, with imprecise and polyvalent concepts, which can make approximate decision processes. The theory of fuzzy logic, or "fuzzy set theory", resembles human reasoning in the use of approximate information and uncertainty to generate decisions. It was specifically designed to mathematically represent uncertainty and imprecision and provide formalized tools to deal with the intrinsic imprecision for many problems (Smith, 1994). In this research, we try to attribute, through fuzzy logic, the weights for the different indicators that can be taken into account for intelligent and sustainable cities, thus obtaining a significant homogeneity and objectivity.

The proposed decision support model based on fuzzy logic provides meaningful solutions and suggestions for identifying strengths and weaknesses in specific aspects of intelligent city management. In addition, the model helps smart cities improve performance, through the analysis of the indicators movement. In summary, one of the key benefits of using this integrated framework as a decision support model, is that it serves as an effective, market-oriented effort that enables smart cities to improve performance and stand out in the fierce market competition.

There will still be questions to be answered, as which ISO 37120 indicators are critical to effectively measuring the sustainability of a system - and whether all the ideal indicators are really already there. Furthermore, which group of indicators is better suited to what level of development of a city (since developed cities can have their bad characteristics "masked" by some indicators with a high numerical level, that already possess the investment and care necessary for their maintenance). In any case, we understand that a global score, mainly comparing cities from the same country (sharing the same cultural, political and HDI reality), can help on defining the best way of investing towards a truly sustainable society.

a) What is a Smart Sustainable City, after all?

As per our understanding, the smart sustainable city concept goes far beyond than a simple modern city idea: it is a complex system where many forces interact to basically (1) receive inputs from the environment (water, air, land, temperature etc.), (2) treat those inputs in a way to generate energy and negative entropy to its inhabitants and to itself and (3) returns a treatable output to the environment (in a feasible way to permit the cycle to happen again). This system has many components, as shown in Figure 3 (that we have named "Sustainability Mandala"):

a) Public Management: the nucleus of the system, responsible for creating and maintaining all the subparts working together. It has to use its governance and inspection capacity to guarantee that all subjects in the system will collaborate to the negative entropy of it.

b) Society: co-responsible for auditing what the subjects of the system are doing, it has a sensitive role: to make changes start from each individual in the system, not only the organizations;

c) Private Companies: responsible for giving space to sustainable development, they have the main role to refrain from creating non-treatable outputs to the environment, acting responsibly and being accountable for their acts ('Public Management' and 'Society' are their main auditors, and all three components shall share feedback);

d) Indicators: a group of variables that receive numeric values and serve as the base to calculate the city general sustainability score (index) - through the adapted SAFE model. Creating ways to measure and keep those variables values updated is fundamental to control and foresee growth. The Sustainability Mandala is flexible enough to receive any kind of indicators - in this article and in Figure 4, we are using the ISO $37120: 2017$ group of indicators;

e) HUMSi: group of indicators that imply on the level of how the Human variables are being treated into the system;

f) ECOSi: group of indicators that imply on the level of how the Ecological variables are being treated into the system;

g) PDCA cycle (Plan, Do, Check and Act): the cycle to which all indicators are subject, at all times, through the effort of Private Companies, Government and Society. It is an effort to enhance the indicators numbers continuously;

h) Technology: the backbone that connects all the components of the system, it provides not only information workflow, but also all kinds of gadgets that will make the system work. It also connects indicators (and their subdivisions) managers and controllers, also making feedback a constant tool for system improvement.

i) Environment INPUTS: water, air, land, temperature;

j) City OUTPUTS: water, air, land, temperature, solid waste, wastewater, health.

k) Cities Interactions: Cities interact. Not only economically, but all kinds of output one city sends to another, can jeopardize the other city's state (like epidemics, solid waste, population and crime migration etc.). The interaction between neighbor cities shall be understood and seen very closely (and so do their effect over the other city indicators), and technology is a great ally on this subject. 


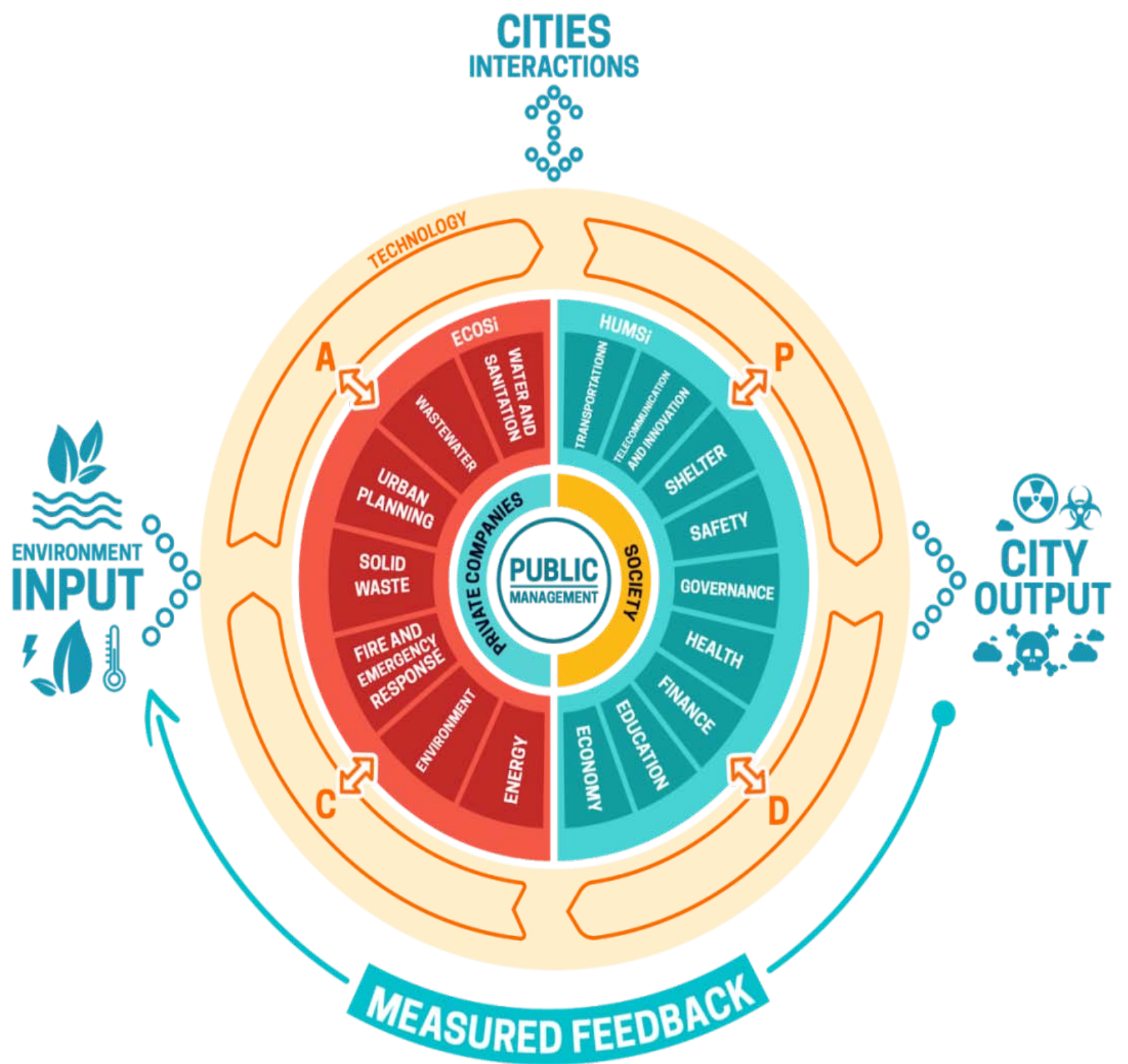

Fig. 3: Sustainability Mandala

The "sustainability mandala" represents a system (city) that is smart and sustainable at the same time. This system is closed in the sense that it can provide all the mechanisms to endurance and thrive in a competition environment, doing it in a sustainable way sustainably by controlling very closely the indicators indexes and their movement. With an implemented neural network, using all the technology wired throughout the system, we can have prediction models that will help decision makers perform better investments on the most responsive indicators - always aiming to enhance the general score. By doing so, the smart city will automatically provide better outputs to the environment (and to the other cities it interacts with), creating a positive chain reaction that will end up reflecting on itself, eventually. The city is the core of the sustainable development and being an example to others will make the first sustainable cities the smartest ones. 


\section{References Références Referencias}

1. Environment, S. F. (2016). Designing a smarter, more sustainable. San Francisco: San Francisco Department of the Environment.

2. United Nations (2014). World urbanization prospects: The 2014 revision, highlights. United Nations: Department of Economic and Social Affairs, Population Division.

3. Smith PN. Applications of Fuzzy sets in the environmental evaluation of projects. J. Environ. Manage. 1994;42(4):365-88.

4. Kennedy, C., Cuddihy, J., \& Engel-yan, J. (2007). of Cities, 11(2).

5. Meijering, J. V., Kern, K., \& Tobi, H. (2014). Identifying the methodological characteristics of European green city rankings. Ecological Indicators, 43, 132- 142.

6. Albino, V., Berardi, U., \& Dangelico, R. (2015). Smart cities: Definitions, dimensions, performance, and initiatives. Journal of Urban Technology, 22(1), 3-21.

7. Bulkeley, H., \& Betsill, M. M. (2005). Rethinking Sustainable Cities: Multilevel Governance and the "Urban" Politics of Climate Change Rethinking Sustainable Cities: Multilevel Governance and the "Urban" Politics of Climate Change. Environmental Politics, 14(February), 42-63. European Commission. (2014). Climate action.. http:// ec.europa.eu/clima/policies/ 2030/index en.htm (Accessed $x x x x$ )

8. Giffinger, R., \& Gudrun, H. (2010). Smart cities ranking: An effective instrument for the positioning of the cities? ACE: Architecture City and Environment, 4, 7-26.

9. American Nacional Standards Institute. Indicators for City Services and Quality of Life in Sustainable Cities and Communities in ISO 37120:2018. August 13, 2018. https://blog.ansi.org/2018/08/indicatorssustainable-city-iso-37120-2018/\#gref (Accessed xxxx)

10. Giffinger, R., \& Haindl, G. (2007). Smart Cities Ranking: an Effective Instrument for the Positioning of Cities?, 703-714. Retrieved from https:// upcommons.upc.edu/bitstream/handle/2099/11933/ 05_PROCEEDINGS_M 5_01_0014.pdf

11. Carretero, M. I. (2002). Clay minerals and their beneficial effects upon human health. A review. Applied Clay Science, 21(3-4), 155-163. https://doi.org/10.1016/S0169-1317(01)00085-0

12. Goodland, R., \& Daly, H. (1996). Environmental Sustainability: Universal and Negotiable. Ecological Applications, 6(4), 1002-1017.

13. Hiremath, R. B., Balachandra, P., Kumar, B., Bansode, S. S., \& Murali, J. (2013). Indicator-based urban sustainability-A review. Energy for Sustainable Development, 17(6), 555-563.

14. Holden, E., Linnerud, K., \& Banister, D. (2017). The Imperatives of Sustainable Development. Sustainable Development, 25(3), 213-226.

15. Jessop, B. (2000). An Entrepreneurial City in Action: Hong Kong's Emerging Strategies in and for (inter) Urban Competition. Urban Studies, 37(12), 2315-2335.

16. Kanter, R. M., \& Litow, S. S. (2009). Informed and Interconnected: A Manifesto for Smarter Cities Informed and Interconnected: A Manifesto for Smarter Cities

17. Elias, S., \& Krogstie, J. (2017). Smart sustainable cities of the future: An extensive interdisciplinary literature review. Sustainable Cities and Society, 31, 183-212.

18. Hopwoodil, B., Mellor, M., \& O'Brein, G. (2005). Sustainable development: Mapping different approaches. Sustainable Development, 13(1), 3852.

19. Jöst, F. (2002). Sustainable development: The roles of science and ethics. In M. Faber, R. Manstetten, \& J. Proops (Eds.), Ecological economics: Concepts and methods (pp. 75-92). Cheltenham: Edward Elgar.

20. Jacobs, M. (1999). Sustainable development as a contested concept. In A. Dobson (Ed.), Fairness and futurity. Oxford: Oxford University Press.

21. Munda, G. (1997). Environmental economics: Ecological economics, and the concept of sustainable development. Environmental Values, 6, 213-233.

22. Redclift, M. (1987). Sustainable development: Exploring the contradictions. London: Methuen.

23. Redclift, M. (2005). Sustainable development (19872005): An oxymoron comes of age. Sustainable Development, 13(4), 212-227

24. Murcott, S. (1997). Definitions of sustainable development. AAAS annual conference, IIASA sustainability indicators symposium.

25. Rai, P. T. (2012). Townships for Sustainable Cities, 37, 417-426.

26. Suzuki, H., Dastur, A., Moffatt, S., Yabuki, N., \& Maruyama, H. (2010). Eco Cities.

27. Marsal-Llacuna, M.-L., Colomer-Llinàs, J., \& Meléndez-Frigola, J. (2015). Lessons in urban monitoring taken from sustainable and livable cities to better address the Smart Cities initiative. Technological Forecasting and Social Change, 90(B), 611-622

28. Mercer. (2014). 2014 quality of living worldwide rankings - mercer survey. new York. http://www.uk.mercer.com/newsroom/2014-qualityof-living-survey.html (accessed xxxx) 
29. Ahvenniemi, H., Huovila, A., Pinto-Seppä, I., \& Airaksinen, M. (2017). What are the differences between sustainable and smart cities? Cities, 60, 234-245.

30. McManus, P. (1996). Contested terrains: Politics, stories and discourses of sustainability. Environmental Politics, 5, 48-73

31. Berardi, U. (2013). Sustainability assessment of urban communities through rating systems. Environment. Development and Sustainability, 15, 1573-1591.

32. Robinson, J., \& Cole, R. (2015). Theoretical underpinnings of regenerative sustainability. Building Research and Information, 43(2), 133-143.

33. Turcu, C. (2013). Re-thinking sustainability indicators: Local perspectives of urban sustainability. Journal of Environmental Planning and Management, 56(5), 695-719.

34. Tanguay, G. A., Rajaonson, J., Lefebvre, J.-F., \& Lanoie, P. (2010). Measuring the sustainability of cities: An analysis of the use of local indicators. Ecological Indicators, 10, 407-418.

35. Hung-Nien, H., Chiu-Yao, C., Chung-Chih, C., \& Yuan-Yu, C. (2011). The evaluating indices and promoting strategies for intelligent city in Taiwan. In Proceedings of the international conference on multimedia technology (ICMT) (pp. 6704-6709).

36. MILANEZ, B.; TEIXEIRA, B.A.N. Proposta de método de avaliação de indicadores de sustentabilidade para gestão de resíduos sólidos urbanos. In: FRANKENBERG, C.L.C. RAYA-RODRIGUEZ, M.T.; CANTELLI, M. (Coord.). Gestão ambiental urbana e industrial. Porto Alegre: EDIPUCRS, 2003. p. 272283.

37. Organisation For Economic Co-Operation And Development (Oecd). 2005 Annual report on sustainable development work in the OECD. 2006. Sustainable Development Studies. Disponível em: $<$ http://www.oecd.org/dataoecd/58/26/36654376.p $\mathrm{df}>$.

38. KAYANO, J.; CALDAS, E.L. Indicadores para O diálogo. In: CACCIA-BAVA, S.; PAULICA, V.; SPINK, P. (Org.). Novos contornos da gestão local: conceitos em construção. Polis: Programa Gestão Pública e Cidadania. São Paulo: FGV/EAESP, 2002. p. 291-308.

39. VAN BELLEN, H.M. Indicadores de sustentabilidade: uma análise comparativa. Rio de Janeiro: FGV, 2005.

40. Francesco Gagliardia, Mariacristina Rosciab, Gheorghe Lazaroiu. Evaluation of sustainability of a city through fuzzy logic. Energy 32 (2007) 795-802.

41. Why Sustainability Is Now the Key Driver of Innovation (NIDOMULU et. al., 2009, pp 57-64)

42. "Brundt Report" - Report of the World Commission on Environment and Development: Our Common Future, Oslo, 1987
43. A life cycle assessment based procedure for development of environmental sustainability indicators for urban water systems (LUNDIN, M.; MORRISON, G.; 2002, p 145-152)

44. ABNT NBR ISO 37120:2017 - Desenvolvimento sustentável de comunidades - Indicadores para serviços urbanos e qualidade de vida (ABNT Associação Brasileira de Normas Técnicas, 2017)

45. Silent Spring (CARSON, Rachel, 1962)

46. Rachel Carson's Silent Spring (YAAKOV GARB, 1995)

47. A Geopolítica do Desenvolvimento Sustentável: um Estudo sobre a Conferência do Rio de Janeiro (OLIVEIRA, Boletim Campineiro de Geografia, v. 2, n. 3, 2012, pp 480)

48. Agenda 21, United Nations Conference on Environment \& Development, Rio de Janeiro, Brasil, 3 a 14 de Junho de 1992.

49. Eco-92: Avanços e Interrogações (NOVAES, Washington, 1992)

50. Igor Shishlov, Romain Morel \& Valentin Bellassen (2016) Compliance of the Parties to the Kyoto Protocol in the first commitment period, Climate Policy, 16:6, 768-782.

51. Environmental Impact Assessment, from Rio-92 to Rio +20 and Beyond (SANCHEZ et. al, 2012)

52. Rio+20 Ou Rio-20? Crônica de um Fracasso Anunciado (GUIMARÃES et. al, 2012).

53. Global Reporting Initiative. (MATROTI; SOUZA, 2011)

54. Sustainability: an ill-defined concept and its assessment using fuzzy logic (PHILLIS e ANDRIANTIATSAHOLINIAINA, 2001)

55. Fuzzy Logic (ZADEH, Lofti - UC Berkeley, 1965)

56. Introduction to Fuzzy Logic (DERNONCOURT, Franck - MIT, 2013)

57. Sociedades e Comunidades Sustentáveis (DIEGUES, Antônio Carlos, USP, 2003);

58. Business models for sustainable innovation: stateof-the-art and steps towards a research agenda (BOONS, Franc e LUDEKE-FREUND, Florian, Elsevier, 2013);

59. Smart Cities in Europe (CARAGLIU, Andrea et. Al., CERS, 2009); 
कำ

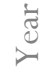

This page is intentionally left blank 